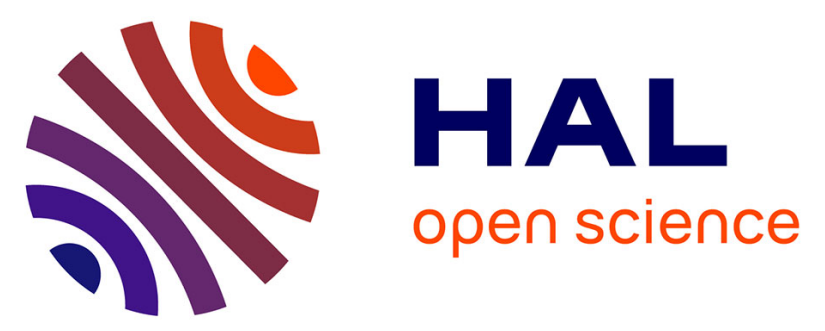

\title{
Spin Crossover and Field-Induced Single-Molecule Magnet Behaviour in Co(II) Complexes Based on Terpyridine with Tetrathiafulvalene Analogues
}

Siham Tiaouinine, Jessica Flores Gonzalez, Bertrand Lefeuvre, Thierry Guizouarn, Marie Cordier, Vincent Dorcet, Lakehmici Kaboub, Olivier Cador, Fabrice Pointillart

\section{To cite this version:}

Siham Tiaouinine, Jessica Flores Gonzalez, Bertrand Lefeuvre, Thierry Guizouarn, Marie Cordier, et al.. Spin Crossover and Field-Induced Single-Molecule Magnet Behaviour in Co(II) Complexes Based on Terpyridine with Tetrathiafulvalene Analogues. European Journal of Inorganic Chemistry, 2021, 2021 (24), pp.2374-2383. 10.1002/ejic.202100247 . hal-03268390

\section{HAL Id: hal-03268390 https://hal.science/hal-03268390}

Submitted on 1 Jul 2021

HAL is a multi-disciplinary open access archive for the deposit and dissemination of scientific research documents, whether they are published or not. The documents may come from teaching and research institutions in France or abroad, or from public or private research centers.
L'archive ouverte pluridisciplinaire HAL, est destinée au dépôt et à la diffusion de documents scientifiques de niveau recherche, publiés ou non, émanant des établissements d'enseignement et de recherche français ou étrangers, des laboratoires publics ou privés. 
WILEY-VCH

\title{
Spin Crossover and Field-Induced Single-Molecule Magnet Behaviour in Co(II) Complexes Based on Terpyridine with Tetrathiafulvalene Analogues
}

\author{
Siham Tiaouinine, ${ }^{\mathrm{a}, \mathrm{b}}$ Jessica Flores Gonzalez, ${ }^{\mathrm{a}}$ Bertrand Lefeuvre, ${ }^{\mathrm{a}}$ Thierry Guizouarn, ${ }^{\mathrm{a}}$ Marie Cordier, ${ }^{\mathrm{a}}$ \\ Vincent Dorcet, ${ }^{a}$ Lakehmici Kaboub, ${ }^{\text {b,c }}$ Olivier Cador, ${ }^{a}$ and Fabrice Pointillart ${ }^{\star a}$
}

\begin{abstract}
Two new TTF-based ligands involving terpyridine moiety $\left(\mathrm{L}^{1}=4-\left(4^{\prime}-\right.\right.$ Methyl-phenyl-2,2:6',2"-terpyridine -4-ylmethylthio)-5-(2cyanoethylthio)-4',5'-bis(methylthio)tetrathiafulvene and $L^{2}=4-\left(4^{\prime}-\right.$ Methyl-phenyl-2,2:6',2"-terpyridine -4-ylmethylthio)-5-(2cyanoethylthio)-4',5'-bis(propylthio)tetrathiafulvene) have been synthesized and seven related mononuclear complexes were isolated as single crystals. The 2:1 (ligand:metal) complexes of formula $\left[\mathrm{Co}\left(\mathrm{L}^{1}\right)_{2}\right]\left(\mathrm{NO}_{3}\right)_{2}(\mathbf{2})$ and $\left[\mathrm{Co}\left(\mathrm{L}^{1}\right)_{2}\right]\left(\mathrm{BF}_{4}\right)_{2}$ (3) displayed thermal spin crossover transition while the 1:1 complexes of formula $\left[\mathrm{CoCl}_{2}\left(\mathrm{~L}^{1}\right)\right](\mathrm{DMF})_{2} \quad(\mathbf{4}), \quad\left[\mathrm{CoBr}_{2}\left(\mathrm{~L}^{1}\right)\right] \cdot(\mathrm{DMF}) \quad$ (5), $\left[\mathrm{CoCl}_{2}\left(\mathrm{~L}^{2}\right)\right] \cdot(\mathrm{DMF}) \cdot 0.5\left(\mathrm{Et}_{2} \mathrm{O}\right)(6)$ and $\left[\mathrm{CoBr}_{2}\left(\mathrm{~L}^{2}\right)\right] \cdot(\mathrm{DMF})(7)$ displayed slow magnetic relaxation through either Raman or Raman/Direct combination processes. A relationship between the structure and the nature of the magnetic relaxation processes is proposed.
\end{abstract}

\section{Introduction}

In molecular magnetism field, both chemist and physicist communities have a great interest for magnetic bistability which can be observed under a wide range of external stimuli. Indeed such magnetic behaviour is at the origin of several potential applications such as switches, sensors and high-density data storage. ${ }^{[1]}$ Spin Crossover (SCO) $)^{[2]}$ and Single-Molecule Magnet $(\mathrm{SMM})^{[3]}$ are probably the most intensively studied magnetic behaviour with molecular bistability.

On one hand, slow magnetic relaxation was observed for the first time in the $90 \mathrm{~s}$ for $\mathrm{a} \mathrm{Mn}_{12}$ cluster and it is associated to the coupling of the large uniaxial anisotropy (D) with the intrinsic spin (S) of the molecule leading to an anisotropy barrier $\left(U=|D| S^{2}\right)$ for the reversal of the magnetization. ${ }^{[4]}$ Then attentions were

[a] S. Tiaouinine, Dr. J. Florès Gonzalez, B. Leufeuvre, M. Cordier, Dr. V. Dorcet, Prof. O. Cador, Dr. F. Pointillart

Univ Rennes, CNRS, ISCR (Institut des Sciences Chimiques de

Rennes) - UMR 6226, F-35000 Rennes, France.

https://iscr.univ-rennes1.fr/fabrice-pointillart\#p-3075

E-mail: fabrice.pointillart@univ-rennes1.fr

[b] S. Tiaouinine, Prof. L. Kaboub.

Laboratory of Organic Materials and Heterochemistry, University of tebessa, Rue de Constantine, 12002 Tébessa, Algeria

[c] Prof. L. Kaboub

Laboratory of Chemistry, Molecular Engineering and

Nanostructures, University of Ferhat Abbas-Sétif 1, 19000 Sétif, Algeria

Supporting information for this article is given via a link at the end of focused on the synthesis of transition metal clusters with the highest possible ground state spin and a strong negative magnetic anisotropy. ${ }^{[3 a][5]}$ Nevertheless, in 2003, the observation of the first magnetic bistability for a mononuclear lanthanide complex opened the route for a new class of SMMs for which the memory effect is based on the magnetic properties of a single metal centre in a given crystal field. ${ }^{[6]}$ The first $3 d$ mononuclear SMM was discovered in 2010 for a four coordinated Fe(II) complex, ${ }^{[7]}$ quickly followed by the extension of such a family of compounds including $\mathrm{Fe}(\mathrm{I}, \mathrm{II}, \mathrm{III}),{ }^{[8]} \mathrm{Co}(\mathrm{I}, \mathrm{II}),{ }^{[9]} \mathrm{Mn}(\mathrm{III}, \mathrm{IV}),{ }^{[10]}$ $\mathrm{Ni}(\mathrm{I}, \mathrm{II}),{ }^{[11]} \mathrm{Cu}(\mathrm{II})^{[12]}$ and $\mathrm{V}(\mathrm{III})^{[13]}$. As for lanthanide, ${ }^{[14]}$ the last discoveries in this research domain suggested that low coordination numbers should be favoured to design compounds displaying slow magnetic relaxation with the highest possible blocking temperature. ${ }^{[15]}$ The reported examples which displayed slow magnetic relaxation involve bi, tri, tetra, penta and hexacoordinated complexes for which the SMM behaviour is observed under an applied magnetic field to cancel the quantum tunnelling of the magnetization (QTM). One of the strategy used by chemists is to associate a Co(II) centre with a tridentate antenna-like ligand such as terpyridine or 2,6-dipyrazole-1-ylpyridine derivatives and two weakly coordinated halides. ${ }^{[16]}$

On the other hand, SCO behaviour was discovered in the $30 \mathrm{~s}^{[17]}$ It can be defined as a change between high-spin (HS) and low-spin (LS) states under the action of various external stimuli such as temperature, light or pressure. ${ }^{[18]}$ The SCO behaviour, especially the magnetic bistability, is not only influenced by the first coordination sphere of the metal or the nature of the complex but also by the crystal packing and the intermolecular interactions such as van der Walls interaction, hydrogen and halogen bonds. In fact such interaction strongly drive the cooperativity of the systems and therefore the observation of abrupt or thermal hysteresis. ${ }^{[19]}$ The most popular candidate for SCO behaviour is the $\mathrm{Fe}(\mathrm{II})$ because the large variation of spin state from paramagnetic $(S=2)$ to diamagnetic $(S=0)$ states. Nevertheless the $\mathrm{Co}$ (II) can also be a good candidate for the design of complexes giving gradual and incomplete thermally induced SCO. ${ }^{[20]}$ Once associated with two terpyridine derivatives, the resulting $\mathrm{Co}(\mathrm{II})$ complex can display either $\mathrm{SCO}^{[21]}$ or SMM behaviour when the $\mathrm{Co}(\mathrm{II})$ remains in its $\mathrm{HS}$ at low temperature ${ }^{[22]}$.

Few examples of $3 d$ SMM and $3 d$ SCO complexes have been published in which the coordinated ligands are decorated with a redox-active moiety such as the tetrathiafulvalene (TTF) ${ }^{[23]}$ core or ferrocenyl group ${ }^{[22 a]}$ in order to modulate the magnetic properties. 


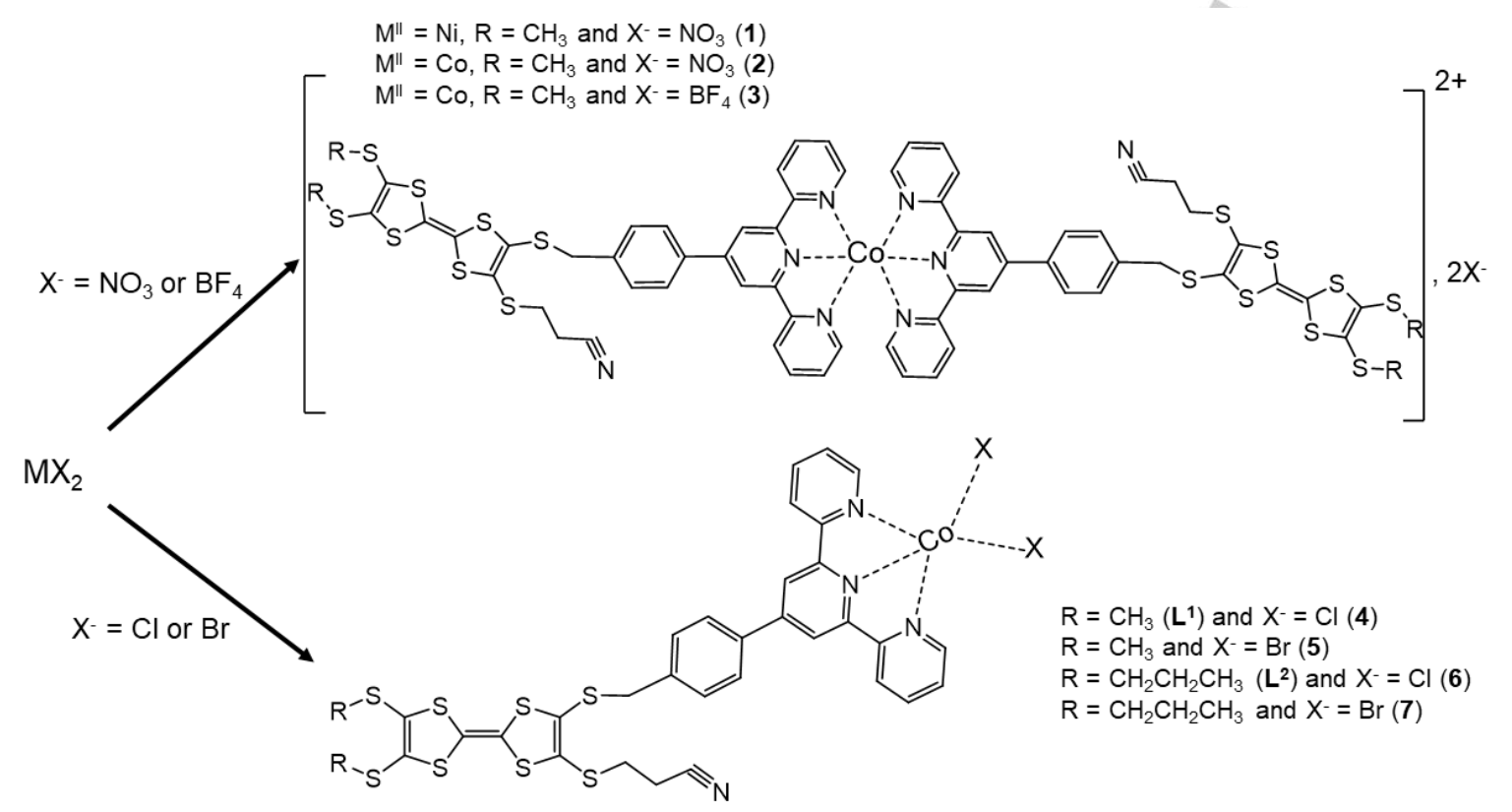

Scheme 1. Synthetic strategies for the formation of the complexes 1-7.

In conclusion terpyridine derivatives can be suitable ligands for Co(II) ions to observe both SMM and SCO behaviour. Thereby, few research groups designed redox-active ligands involving the two TTF core and terpyridine functionalization as well as their corresponding transition metal complexes. Nevertheless neither SMM nor SCO behaviours were observed. ${ }^{[24]}$ Thus the two ligands 4-(2,2':6',2"-terpyridine-4-ylmethylthio)-5-(2cyanoethylthio)-4', $5^{\prime}$-bis(methylthio)tetrathiafulvalene $\left(L^{1}\right)$ and $4-$ (2,2':6',2"-terpyridine-4-ylmethylthio)-5-(2-cyanoethylthio)-4',5'bis(propylthio)tetrathiafulvalene $\left(\mathrm{L}^{2}\right)$ were selected for coordination reaction in presence of $\mathrm{Co}$ (II) salts with the aim of observing such magnetic behaviours. When starting with nitrate or tetrafluoroborate salts of $\mathrm{Ni}(\mathrm{II})$ or $\mathrm{Co}(\mathrm{II})$ the $1: 2$ complexes of formula $\left[\mathrm{Ni}\left(\mathrm{L}^{1}\right)_{2}\right]\left(\mathrm{NO}_{3}\right)_{2}(\mathbf{1}),\left[\mathrm{Co}\left(\mathrm{L}^{1}\right)_{2}\right]\left(\mathrm{NO}_{3}\right)_{2}(\mathbf{2})$ and $\left[\mathrm{Co}\left(\mathrm{L}^{1}\right)_{2}\right]\left(\mathrm{BF}_{4}\right)_{2}$ (3) have been obtained while when starting from chloride or bromide salts $1: 1$ complexes of formula $\left[\mathrm{CoCl}_{2}\left(\mathrm{~L}^{1}\right)\right](\mathrm{DMF})_{2}(4)$, $\left[\mathrm{CoBr}_{2}\left(\mathrm{~L}^{1}\right)\right] \cdot(\mathrm{DMF}) \quad$ (5), $\quad\left[\mathrm{CoCl}_{2}\left(\mathrm{~L}^{2}\right)\right] \cdot(\mathrm{DMF}) \cdot 0.5\left(\mathrm{Et}_{2} \mathrm{O}\right) \quad$ (6) and $\left[\mathrm{CoBr}_{2}\left(L^{2}\right)\right] \cdot(\mathrm{DMF})(7)$ were isolated (Scheme 1). The X-ray structures on single crystal were determined for the seven complexes and their electrochemical as well as magnetic properties were studied.

\section{Results and Discussion}

\section{Description of the Structures}

$\left[\mathrm{M}\left(\mathrm{L}^{1}\right)_{2}\right]\left(\mathrm{NO}_{3}\right)_{2}(\mathrm{M}=\mathrm{Ni}(\mathrm{II})$ (1) and $\mathrm{Co}$ (II) (2)). Both compounds crystallize in the triclinic P-1 (N²) space group (Table S1). The asymmetric unit is composed of a whole complex $\left[\mathrm{M}\left(\mathrm{L}^{1}\right)_{2}\right]\left(\mathrm{NO}_{3}\right)_{2}$ (Figures $\mathrm{S} 1$ and $\mathrm{S} 2$ ). Two ligands $\mathrm{L}^{1}$ coordinate the $\mathrm{M}(\mathrm{II})$ centre leading to a compressed octahedral coordination sphere. The compression is identified along the axis made by the central pyridine rings and the metal centre with an average $\mathrm{M}-\mathrm{N}$ distances of (1.965(8) $\AA$ for 1 and 1.884(6) $\AA$ for 2) while the orthogonal average $\mathrm{M}-\mathrm{N}$ distances are measured to 2.102(7) $\AA$ for $\mathbf{1}$ and 2.074(5) $\AA$ for 2. The phenyl-terpyridine aromatic system is not planar while the TTF core is flat. The central $\mathrm{C}=\mathrm{C}$ bond lengths, ranging from $1.326(15)$ to $1.355(15) \AA$, for both TTF cores in the two complexes are in agreement with a neutral form. ${ }^{[25]}$ The arrangement of the ligand $\mathrm{L}^{1}$ might be driven by the short contacts between the nitrile groups and the pyridine moieties $(\mathrm{N} \cdots \mathrm{H}$ contacts ranging from $2.846 \AA$ to $3.103 \AA$ ).

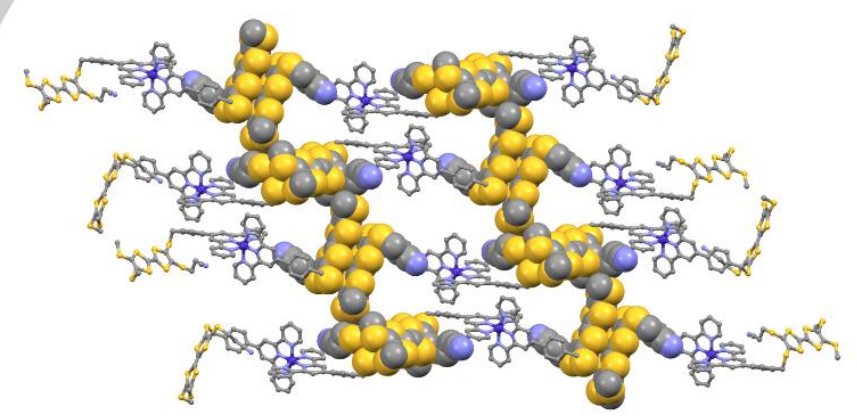

Figure 1. Crystal packing for 2 highlighting the formation of dimers between the TTF derivatives along the $b$ axis. The stacked TTF derivatives are drawn in "spacefill" representation while the bis(phenylterpyridine)Co(II) fragments are drawn in "ball and sticks" representation.

The crystal packing of $\mathbf{1}$ and $\mathbf{2}$ displayed "head-to-tail" dimerization of the TTF derivatives along the $b$ axis (Figure 1) with S...S contacts shorter than the sum of the van der Waals radii for such atoms (3.501-3.507 $\AA$ ). The inorganic part of the molecular 
system i.e. the metallic bis(phenyl-terpyridine) part, is stacked through $\pi-\pi$ interactions.

$\left[\mathrm{Co}\left(\mathrm{L}^{1}\right)_{2}\right]\left(\mathrm{BF}_{4}\right)_{2}(3)$. The replacement of the nitrate anions with tetrafluoroborate ones did not induce significant modification at the molecular complex point of view (Figures 2 and S3). Similar 2:1 ( $\left.\mathrm{L}^{1}: \mathrm{Co}\right)$ coordination complex in which the $\mathrm{Co}$ (II) centre lies in a compressed octahedral sphere is formed and crystallizes in the triclinic P-1 space group (Table S1).

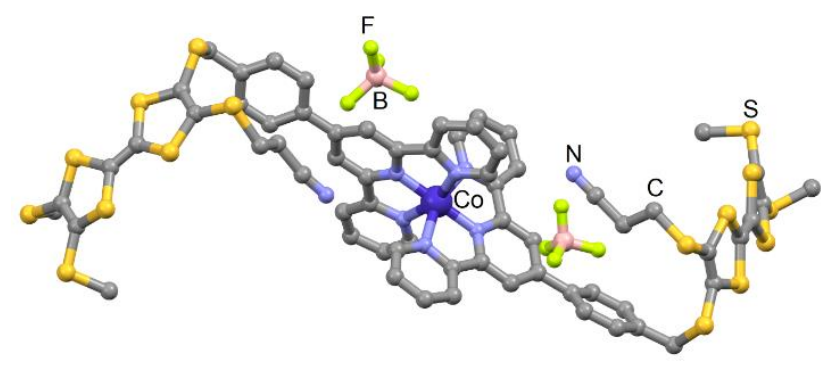

Figure 2. Molecular X-ray structure of 3. Colour code: grey (carbon), blue (nitrogen), light pink (boron), yellow (sulphur), light green (fluorine) and dark blue (cobalt). Hydrogen atoms have been omitted for clarity.

The main modification could be observed at the crystal packing point of view. Indeed, tetramers of TTF derivatives are formed (Figure 3 ) instead of dimers. The shortest S...S contacts have been found equal to $3.753 \AA$ between the two non-parallel TTF cores while they are equal to $3.840 \AA$ for the two "head-to-tail" TTF cores. The two non-parallel and two "head-to-tail" TTF cores constitute one tetramer.

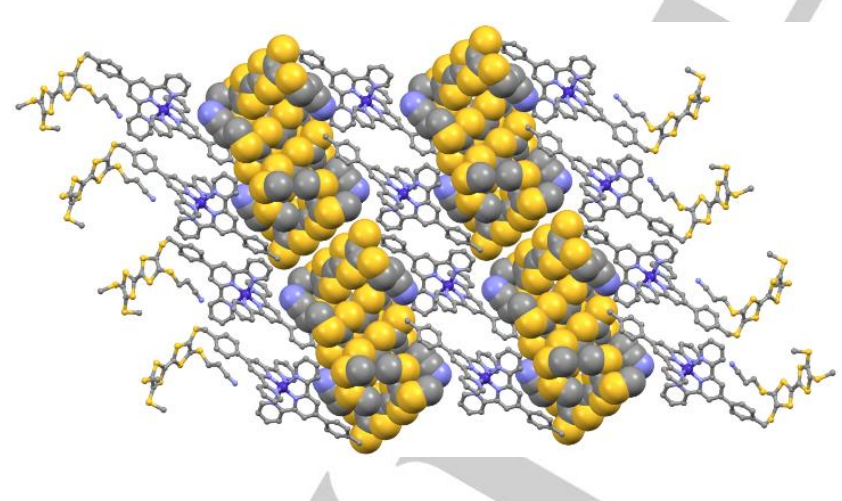

Figure 3. Crystal packing of 3 highlighting the formation of tetramers of TTF derivatives. The stacked TTF derivatives are drawn in "spacefill" representation while the bis(phenylterpyridine)Co(II) fragments are drawn in "ball and sticks" representation.

$\left[\mathrm{CoCl}_{2}\left(\mathrm{~L}^{1}\right)\right](\mathrm{DMF})_{2}(4)$. Changing the nitrate or tetrafluoroborate anions with halogen anions such as chloride or bromide led to the formation of $1: 1$ (Co: $\mathrm{L}^{1}$ ) coordination complexes. Complex 4 crystallized in the monoclinic space group $\mathrm{C} 2 / \mathrm{c}\left(\mathrm{N}^{\circ} 15\right)$ (Table S1). The asymmetric unit is composed of one neutral complex of formula $\left[\mathrm{CoCl}_{2}\left(\mathrm{~L}^{1}\right)\right]$ and two dimethylformamide (DMF) solvent molecules of crystallization (Figures 4 and S4). The Co(II) is surrounded by three nitrogen atoms coming from the $L^{1}$ ligand while the coordination sphere is completed by two coordinated chloride anions. The Co-N distances range from 2.038(3) to 2.177(4) A while the Co-Cl bond lengths are similar (2.279(1) and $2.280(1) \AA$ ). The arrangement of the ligands around the Co(II) induced a trigonal bipyramid geometry for which the trigonal base is formed by the two chlorides and the nitrogen atom of the central pyridine ring.

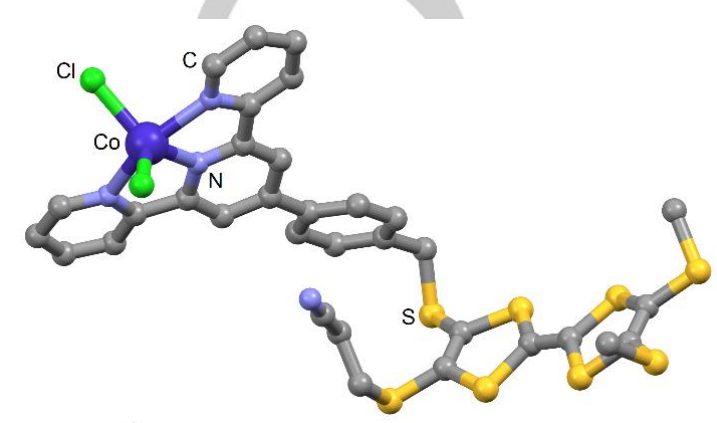

Figure 4. Molecular X-ray structure of 4. Colour code: grey (carbon), blue (nitrogen), yellow (sulphur), green (chloride) and dark blue (cobalt). Both hydrogen atoms and DMF molecules have been omitted for clarity.

As for the 2:1 ( $\left.\mathrm{L}^{1}: \mathrm{M}\right)$ complexes, the phenyl-terpyridine aromatic system is not planar while the TTF core is flat. The central $\mathrm{C}=\mathrm{C}$ bond length, being equal to $1.342(5) \AA$ is in agreement with the neutral form. ${ }^{[25]}$ No $\mathrm{N} \cdots \mathrm{H}$ contacts were identified between the nitrile group and the pyridine moieties nevertheless, both nitrile groups and the phenyl ring are interacting through their $\pi$ conjugated systems.
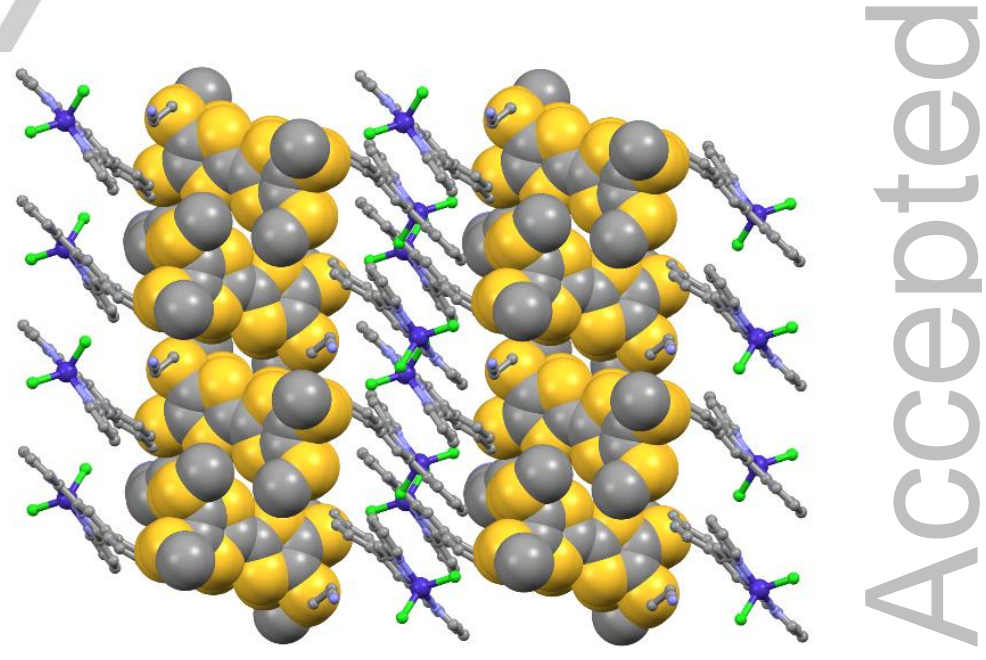

Figure 5. Crystal packing of $\mathbf{4}$ highlighting the formation of tetramers of TTF derivatives. The TTF derivatives are drawn in "spacefill" representation while the phenylterpyridine $\mathrm{CoCl}_{2}$ units are drawn in "ball and sticks" representation.

The crystal packing displayed the formation of a monodimensional network of stacked TTF derivatives along the $c$ axis. 
The crystal packing displayed the formation of "head-to-tail" dimers through S...S contacts $(3.730 \AA)$ interacting with neighbouring dimers through lateral S...S contacts $(3.864 \AA)$ which led to the formation of a mono-dimensional network of stacked TTF derivatives along the $c$ axis (Figure 5). The phenylterpyridine $\mathrm{CoCl}_{2}$ units are stacked through $\pi-\pi$ interactions.

$\left[\mathrm{CoBr}_{2}\left(\mathrm{~L}^{1}\right)\right]$.(DMF) (5). Once the chloride ligands replaced by bromide ones, the complex $\mathbf{5}$ crystallizes in the monoclinic space group C2/c (Table S1). The Co(II) retained its trigonal bipyramidal coordination sphere with the two bromides and the nitrogen atom of the central pyridine forming the trigonal base (Figure S5). While the Co-N bond lengths remain similar to those of compound 4 , the Co-Br distances are longer (2.429(1) $\AA$ ) than the Co-Cl distances. The TTF core is now adopting a boat conformation which could be an indication of a different crystal packing. Indeed, dimers of ligands are formed, but only half of the TTF core realizes short S...S contacts $(3.453 \AA$ ). In other words, the two TTF core forming the dimer are shifted. Each TTF core of a dimer performed lateral S...S contacts $(3.655 \AA$ ) with another neighbouring TTF core leading to the formation of a $2 \mathrm{D}$ layer of TTF core in the plan (110) (Figure S6).

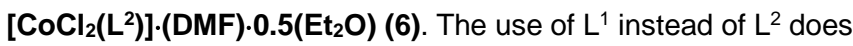
not show significant change in the X-ray structure of 6 compared to 4 (Tables S1, Figure S7). The Co(II) adopting a trigonal bipyramidal coordination sphere, the TTF is rather planar and the nitrile group and the phenyl ring are interacting through their $\pi$ systems. The crystal packing highlighted the formation of monodimensional network of stacked TTF derivatives along the $c$ axis owing to the fact "head-to-tail" TTF-based dimers (S...S contacts, $3.742 \AA$ ) and lateral S...S contacts (3.683 $\AA$ ) (Figure S8). The latter have been found to be slightly shorter than those of 4 . The "CoCl ${ }_{2}$ terpyridine" units are stacked through $\pi-\pi$ interactions of two pyridine rings.

$\left[\mathrm{CoBr}_{2}\left(\mathrm{~L}^{2}\right)\right]$.(DMF) (7). The bromide derivative crystallizes in the monoclinic space group $\mathrm{P} 2 / \mathrm{n}\left(\mathrm{N}^{\circ} 14\right)$ (Table S1). The asymmetric unit is composed from two $\left[\mathrm{CoBr}_{2}\left(\mathrm{~L}^{2}\right)\right]$ complexes (Figure 6) and two DMF molecules of crystallization (Figure S9). The Co1 and Co2 metal centres adopt respectively a trigonal bipyramidal and square pyramidal coordination sphere with the two bromides and the nitrogen atom of the central pyridine forming the trigonal base

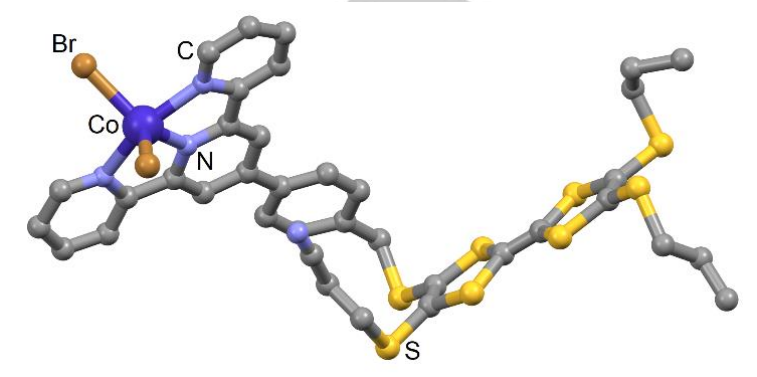

Figure 6. Molecule structure of one complex of 7 involving the $\mathrm{Co}$ (II) ion in the trigonal bipyramidal geometry. Hydrogen atoms and DMF molecule of crystallization have been omitted for clarity. while the square base is formed by the three nitrogen of the terpyridine moiety and one bromide. The Co1- $\mathrm{Br}(2.428(13) \AA)$ and $\mathrm{Co} 2-\mathrm{Br}(2.435(12) \AA)$ distances are similar as well as the average Co1-N (2.108(6) $\AA$ ) and Co2-N (2.112(6) $\AA$ ) distances. Both TTF cores are planar and the central $C=C$ bond lengths $(1.352(11) \AA)$ are in good agreement with the neutral form of the ligand. ${ }^{[25]}$ The crystal packing is formed of a $1 \mathrm{D}$ organic subnetwork involving "head-to-tail" dimers of TTF derivatives (Figure 7) with short S...S contacts (3.616 $\AA$ ) while other shorter S...S contacts $(3.492 \AA)$ have been identified between two neighbouring dimers. Finally the $\mathrm{CoBr}_{2}$ terpyridine units showed significant $\pi$ overlapping.

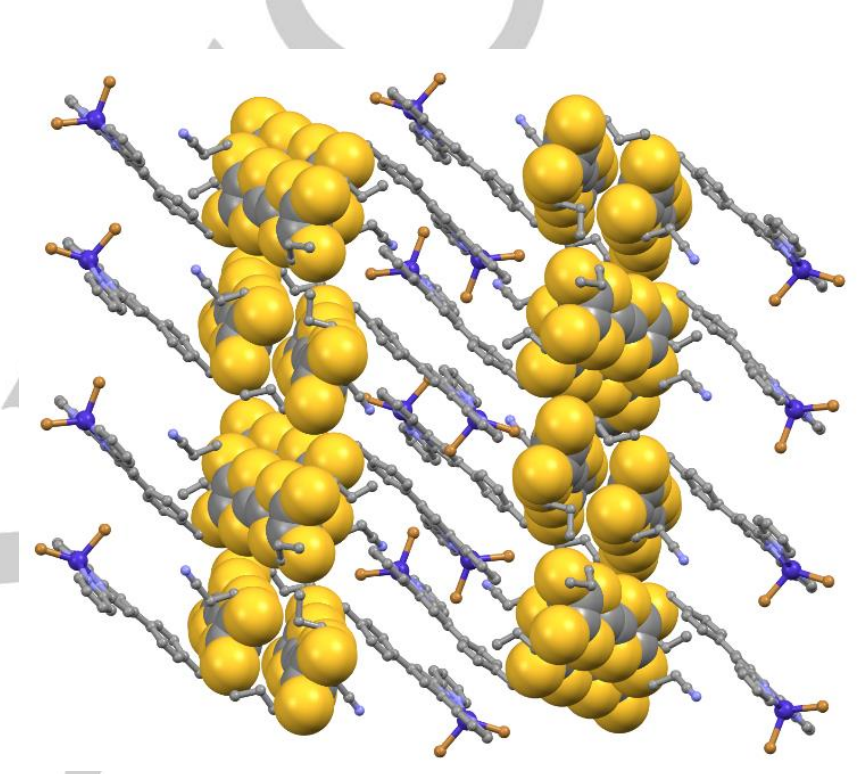

Figure 7. Crystal packing of 7 highlighting the formation of dimers of TTF derivatives. The TTF derivatives are drawn in "spacefill" representation while the phenylterpyridine $\mathrm{CoBr}_{2}$ units are drawn in "ball and sticks" representation.

In conclusion for the structural part, the overall shape of the coordination complexes is kept along the 1-3 and 4-7 series nevertheless, the chemical modification of the TTF-based ligand (SMe versus $\mathrm{SPr}$ ) and the nature of the halogen atoms $(\mathrm{Cl}$ versus $\mathrm{Br}$ ) induced variations in the conformation of the TTF (planar versus boat form), the S...S contacts (dimer versus tetramers) and the $\pi$ overlapping between the $\mathrm{CoX}_{2}$ terpyridine units.

\section{Electrochemical properties.}

The redox properties of $L^{1}$ and $L^{2}$ as well as for the related complexes were investigated by cyclic voltammetry (Figure S10) and the oxidation potentials are listed in Table S2. The two uncoordinated ligands display two monoelectronic oxidations at 0.55 and $0.92 \mathrm{~V}$ (for $L^{1}$ ) and 0.53 and $0.88 \mathrm{~V}$ (for $\mathrm{L}^{2}$ ) attributed to the formation of the radical cation and dication species of the TTF core. The complex 1 presents also these two oxidation waves at 0.69 and $0.84 \mathrm{~V}$ while no redox behaviour was observed for the $\mathrm{Ni}(\mathrm{II})$ centre. For the $\mathrm{Co}$ (II) analogues, the two monoelectronic oxidations centred on the TTF core are observed at 0.69 and 0.86 
$\mathrm{V}$ for 2 and 0.68 and $0.83 \mathrm{~V}$ for $\mathbf{3}$ while the additional reversible monoelectronic oxidation was observed at $0.29 \mathrm{~V}$ and attributed to the oxidation of the $\mathrm{Co}$ (II) into $\mathrm{Co}$ (III) ion ${ }^{[26]}$ as also confirmed by its absence for the $\mathrm{Ni}(\mathrm{II})$ analogue. For the complexes 4-7, the TTF-centred oxidation waves are observed but the oxidation of the $\mathrm{Co}$ (II) to $\mathrm{Co}$ (III) is found to be shifted to higher potentials i.e. $1.05 \mathrm{~V}$ for the chloride derivative (complexes 4 and 6 ) and $0.75 \mathrm{~V}$ $\left({ }^{\circ} E_{1 / 2}\right)$ for the bromide derivatives (complexes 5 and 7). The $\mathrm{Co}$ (II) oxidation wave appears as almost irreversible. It is worth to notice that the oxidation potential at about $0.29 \mathrm{~V}$ is also observed for the four complexes 4-7, indicating the formation of the $1: 2$ (metal:ligand) complexes in DMF solutions. Finally, the slight anodic shifts taking place for the TTF-centred oxidation in the complexes could be attributed to a solvent effect $\left(\mathrm{CH}_{2} \mathrm{Cl}_{2}\right.$ for free ligands, DMF for complexes) because no electronic communication occurs between the TTF core and the metal.

\section{Magnetic properties}

Static dc magnetic measurements. The $\chi_{M} T$ vs $T$ plots $\left(\chi_{M}\right.$ is the molar magnetic susceptibility and $T$ is the temperature expressed in Kelvin) for complexes 1-3 and 4-7 are represented respectively in Figure 8 and S11. Complex 1 displays a room temperature value of $1.13 \mathrm{~cm}^{3} \mathrm{~K} \mathrm{~mol}^{-1}$ in agreement with one $\mathrm{Ni}(\mathrm{II})$ centre with $S=1$ and $g=2.13$. Lowering the temperature, the $\chi_{M} T$ value remains constant down to $15 \mathrm{~K}$ then decreases to $0.86 \mathrm{~cm}^{3}$ $\mathrm{K} \mathrm{mol}^{-1}$ at $2 \mathrm{~K}$ due to the magnetic anisotropy and/or intermolecular interaction.

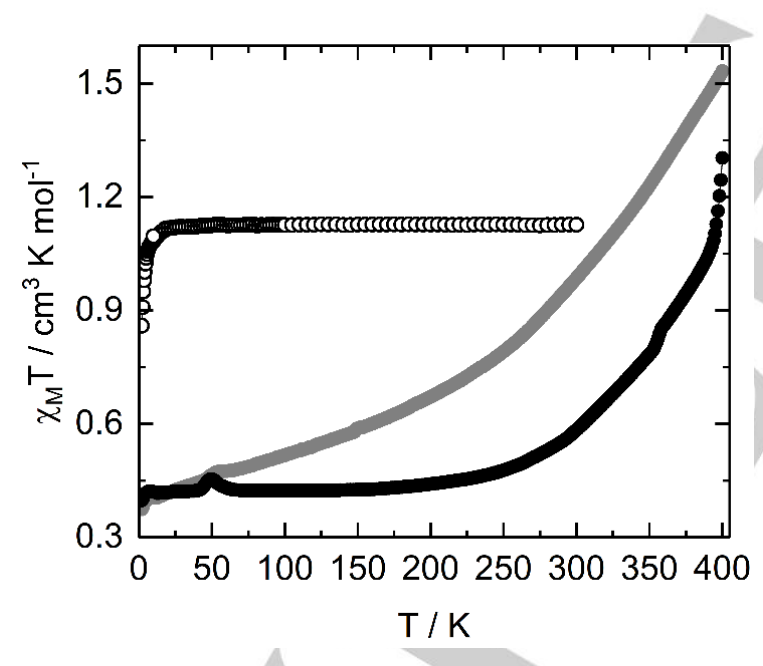

Figure 8. Temperature-dependent dc magnetic susceptibility plots for $\mathbf{1}$ (open black circles), $\mathbf{2}$ (full black circles) and $\mathbf{3}$ (full grey circles).

The two Co(II) derivatives displayed very gradual spin-crossover spin-transition with $\chi_{M} T$ products equal to $0.41 \mathrm{~cm}^{3} \mathrm{~K} \mathrm{~mol}^{-1}$ at very low temperature in agreement with one low-spin state $\mathrm{Co}$ (II) centre $(S=1 / 2 \text { and } g \text { close to } 2)^{[27]}$ while the $\chi_{M} T$ value reaches $1.30 \mathrm{~cm}^{3} \mathrm{~K} \mathrm{~mol}^{-1}$ (for 2) and $1.53 \mathrm{~cm}^{3} \mathrm{~K} \mathrm{~mol}^{-1}$ (for 3) at $400 \mathrm{~K}$ (Figure 8). The thermal spin-transition is incomplete since the expected $\chi_{M} T$ value for fully high-spin $\left[\mathrm{Co}(\text { terpy })_{2}\right]^{2+}$ compounds is close to $2.5 \mathrm{~cm}^{3} \mathrm{~K} \mathrm{~mol}^{-1}{ }^{[27][28]}$ so the compounds 2 and $\mathbf{3}$ are ca. $45 \%$ and $55 \%$ high-spin at $400 \mathrm{~K}$. One could deduce that the nature of the counter ion has an influence on the shape of the thermal spin-transition. Indeed, the nitrate derivative (compound 2) displays a less gradual transition with a clear low-spin state on the $2-200 \mathrm{~K}$ temperature range while the tetrafluoroborate derivative (compound 3 ) reaches its low spin state only at cryogenic temperature.

The magnetization curves for all three complexes at $2 \mathrm{~K}$ in the 0 $50 \mathrm{kOe}$ field range are depicted in Figure S12. The values at 50 $\mathrm{kOe}$ are close the expected saturation values for $\mathrm{Ni}(\mathrm{II})(\mathrm{S}=1)$ and low spin state $\mathrm{Co}(\mathrm{II})(\mathrm{S}=1 / 2)$.

The $\chi_{M} T$ room temperature values are equal to $2.73,2.71,2.79$ and $2.71 \mathrm{~cm}^{3} \mathrm{~K} \mathrm{~mol}^{-1}$ for 4 to 7 (Figure S11) respectively in agreement with the experimentally observed value for Co(II) in pentacoordinated environment ${ }^{[29]}$ and higher than expected for $\mathrm{S}$ $=3 / 2$ spin only system $\left(1.88 \mathrm{~cm}^{3} \mathrm{~K} \mathrm{~mol}^{-1}\right)$. On cooling, the $\chi_{M} T$ vs. $\mathrm{T}$ curves highlight a monotonic decrease due to the depopulation of the $S=3 / 2$ sublevels to reach values $1.80,1.68,1.97$ and 1.54 $\mathrm{cm}^{3} \mathrm{~K} \mathrm{~mol}^{-1}$ for 4 to 7 respectively at $2 \mathrm{~K}$.

The magnetization curves for all four complexes at $2 \mathrm{~K}$ in the 0 $50 \mathrm{kOe}$ field range are depicted in the Figure S13. None of these curves saturate up to $50 \mathrm{kOe}$ and the almost linear increase at high fields might indicate the presence of low-lying states.

Dynamic ac magnetic measurements. None of the complexes 1-3 display an out-of-phase signal on AC susceptibility down to 2 $\mathrm{K}$ without or in applied magnetic field in the frequency range 1 . $10000 \mathrm{~Hz}$ in agreement with an octahedral $\mathrm{Ni}(\mathrm{II})$ and low-spin state $\mathrm{Co}$ (II) ions. As for the previous systems, the complexes 4-7 did not display any slow magnetic relaxation of their magnetization in zero applied magnetic field. However, slow magnetic relaxation is induced by application of an external field in the frequency range $1-10000 \mathrm{~Hz}$ (Figures S14-S17).

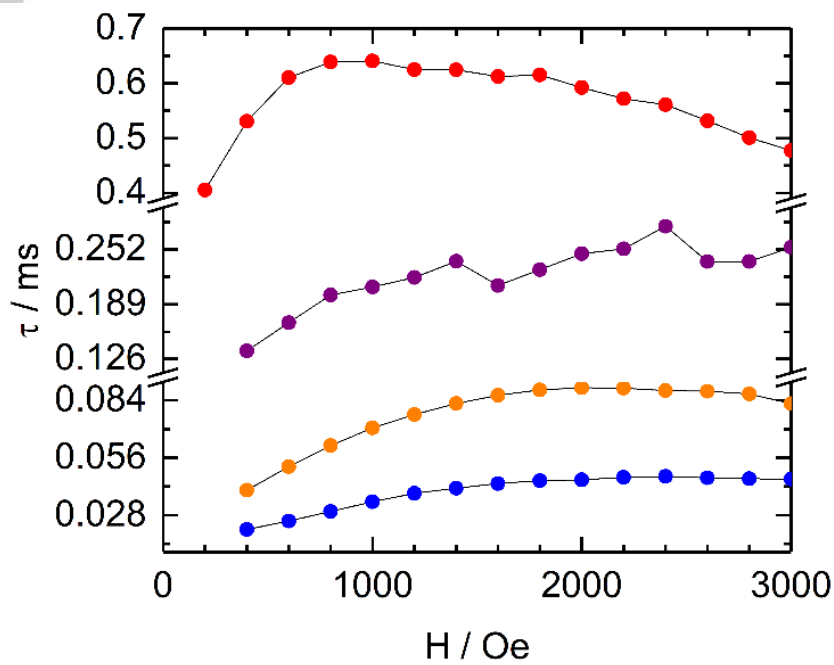

Figure 9. Field dependence of the relaxation time at $2 \mathrm{~K}$ for 4 (blue spots), 5 (red spots), 6 (orange spots) and 7 (purple spots). Black lines are guidelines for eyes. 
Table 1. Parameters giving the best fit of the thermal dependence of the relaxation time for 4-7.

\begin{tabular}{|l|l|l|l|l|}
\hline & $\mathbf{4}$ & $\mathbf{5}$ & $\mathbf{6}$ & $\mathbf{7}$ \\
\hline Raman & $\begin{array}{l}\mathrm{B}=5741(101) \mathrm{s}^{-1} \mathrm{~K}^{-1.99} \\
\mathrm{n}=1.99(2)\end{array}$ & $\begin{array}{l}\mathrm{B}=13.9(11) \mathrm{s}^{-1} \mathrm{~K}^{-5.00} \\
\mathrm{n}=5.00(5)\end{array}$ & $\begin{array}{l}\mathrm{B}=2060(98) \mathrm{s}^{-1} \mathrm{~K}^{-2.40} \\
\mathrm{n}=2.40(4)\end{array}$ & $\begin{array}{l}\mathrm{B}=46.3(16) \mathrm{s}^{-1} \mathrm{~K}^{-4.67} \\
\mathrm{n}=4.67(23)\end{array}$ \\
\hline Direct & $/$ & $\mathrm{A}=5.94(20) \times 10^{-10}$ & $/$ & $\mathrm{A}=4.11(76) \times 10^{-11}$ \\
\hline
\end{tabular}

For the four complexes, the intensity of the out-of-phase signal of the magnetic susceptibility grows with the magnetic field. The optimal magnetic field values were selected as the maxima of the $\tau$ vs $\mathrm{H}$ curves (Figure 9 and Tables S3-S6). Quantitative analysis can be performed at the optimal field of $1700 \mathrm{Oe}$ (for 4), $1000 \mathrm{Oe}$ (for 5), 2000 Oe (for 6) and 2200 Oe (for 7) by varying the temperature (Figures S18-S21). At this point it is important to mention that the slow magnetic relaxation fraction has been determined equal to more than $90 \%$ of the magnetic susceptibility for compounds 4-7 from the normalized Cole-Cole plot (Figures S22-S25). The data have been analysed in the framework of the extended Debye model (Figures S26-S29, Tables S7-S10). The temperature dependence of the relaxation time is represented in Figure 10. In a magnetic relaxation time point of view, the use of $\mathrm{Br}$ - (5 and 7) in the coordination sphere of the Co(II) seems to be more favourable than $\mathrm{Cl}$ - (4 and 6).

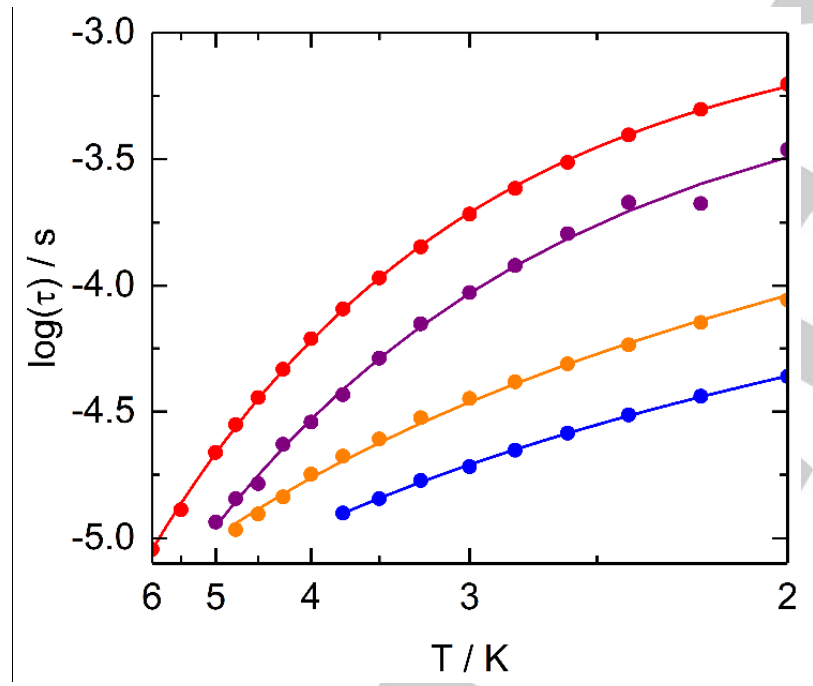

Figure 10. Temperature dependence of the relaxation time for $\mathbf{4}$ (blue spots), $\mathbf{5}$ (red spots), 6 (orange spots) and 7 (purple spots) at the optimal field (see text for values) in the temperature range of 2-3.75 K (for 4), $2-6 \mathrm{~K}$ (for 5), $2-4.75 \mathrm{~K}$ (for 6 ) and $2-5 \mathrm{~K}$ (for 7 ). The full line are the best-fitted curve with Raman (for 4 and 6) and the combination Raman + direct processes (for $\mathbf{5}$ and 7) (see text for parameters).

The equation depicted below allows the fitting of the temperature variation of the relaxation time:

$\tau^{-1}=A H^{m} T+B T^{n}$ where the first and second term starting from the left hand side of the equation are respectively the direct and Raman processes. It is worth to notice that for Kramer ions, the $\mathrm{m}$ parameter is fixed to 4 while $n$ is equal to 9 for Raman process operating through acoustic phonons (lattice vibrations) however this value could be much lower when optical phonons (molecular vibrations) are involved in the magnetic relaxation mechanism. ${ }^{[14 b]}$ The combination of Raman and Direct processes allows to reproduce the experiment for 5 and $\mathbf{7}$ (Figures S30-31 and Table 1) with the parameters depicted in Table 1 while a Raman only is enough to fit the thermal dependence of the relaxation time for $\mathbf{4}$ and $\mathbf{6}$ (Table 1). It is important to notice that the effective energy barrier values and relaxation times were extracted from the data at the high temperature region (Full green line on Figures S32-S35). Attempts to fit the thermal dependences of the relaxation time with a combination of Orbach and Raman processes demonstrated the non-significant implication of the Orbach process on the relaxation of the magnetization for 4-7 (Figure S32-35). Moreover, the $\alpha$ values (where $\alpha$ represents the distribution of relaxation times) range from 0 to 0.3 for high and low temperatures respectively (Tables S7-S10). Such values are in agreement with a single relaxation pathway at low temperature while more relaxation pathways could operate at $2 \mathrm{~K}$. The absence of Quantum Tunnelling of the Magnetization (QTM) is justified by the slow magnetic relaxations observed under applied magnetic field while the non-significant contribution of the Orbach process is in agreement with pentacoordinated $\mathrm{Co}(\mathrm{II})$ in N3X2 environment (X $=\mathrm{Cl}, \mathrm{Br}) .{ }^{[16 \mathrm{c}]}$ One could remark that for the two compounds including $\mathrm{Br}^{-}$in the coordination sphere of the $\mathrm{Co}$ (II) (5 and 7), a significant Direct contribution is involved in the magnetic relaxation mechanism while it is not the case for the two compounds including $\mathrm{Cl}^{-}$(4 and 6). For the four compounds, $n$ was found lower than the expected value for a Co(II) Kramers ion indicating the participation of optical phonons (molecular vibrations) in the Raman process. Nevertheless the $n$ values were found much lower in $\mathbf{4}$ and $\mathbf{6}$ compared to $\mathbf{5}$ and $\mathbf{7}$ that might be due to a greater participation of the optical phonons in the magnetic relaxation because of the difference of $\mathrm{Co}-\mathrm{Cl}$ and $\mathrm{Co}-\mathrm{Br}$ vibration modes.

\section{Conclusions}

In this article, two new TTF-based ligands involving terpyridine moiety have been synthesized. The choice of the starting metallic salt is crucial to obtain either $\left[\mathrm{M}\left(\mathrm{L}^{1}\right)_{2}\right]^{2+}(\mathrm{M}=\mathrm{Ni}$, Co) or $\left[\mathrm{CoX}_{2}\left(\mathrm{~L}^{\mathrm{n}}\right)\right](\mathrm{X}=\mathrm{Cl}, \mathrm{Br}$ and $\mathrm{n}=1,2)$ with nitrate, tetrafluoroborate salts or chloride, bromide salts respectively. 
While the 2:1 (ligand:metal) complexes of formula $\left[\mathrm{Co}\left(\mathrm{L}^{1}\right)_{2}\right]\left(\mathrm{NO}_{3}\right)_{2}$ and $\left[\mathrm{Co}\left(\mathrm{L}^{1}\right)_{2}\right]\left(\mathrm{BF}_{4}\right)_{2}$ displaying thermal spin crossover transition, the $1: 1$ complexes of formula $\left[\mathrm{CoX}_{2}\left(\mathrm{~L}^{\mathrm{n}}\right)\right]$ displayed slow magnetic relaxation. The latter occurred through Raman or Raman/Direct combination depending of the nature of the halide coordinated to the $\mathrm{Co}$ (II) centre. Finally a dependence of the $\mathrm{n}$ exponent value with the halide is observed.

\section{Experimental Section}

General: The precursors 4'-[4-(bromomethyl)phenyl]-2,2':6',2"-terpyridine, 4,5-bis(2-cyanoethylthio)-4',5'-bis(methylthio)tetrathiafulvalene and 4,5bis(2-cyanoethylthio)-4',5'-bis(propylthio)tetrathiafulvalene were synthesized following previously reported methods. ${ }^{[30],[31]}$ All other reagents were purchased from Aldrich and used without further purification All solid-state characterization studies (elementary analysis, IR, magnetic susceptibility) were performed on dried samples and are considered without solvent of crystallization.

\begin{abstract}
4-(4'-Methyl-phenyl-2,2:6',2'-terpyridine -4-ylmethylthio)-5-(2cyanoethylthio)-4',5'-bis(methylthio)tetrathiafulvene ( $\left.\mathrm{L}^{1}\right)$ : 4,5-bis(2cyanoethylthio)-4',5'-bis(methylthio)tetrathiafulvalene ${ }^{[31]}(0.320 \mathrm{~g}, \quad 0.69$ $\mathrm{mmol}$ ) was dissolved in anhydrous degassed $\mathrm{MeOH}(8 \mathrm{~mL})$ under argon. Then $\mathrm{CsOH} \cdot \mathrm{H}_{2} \mathrm{O}(115 \mathrm{mg}, 0.69 \mathrm{mmol})$ in dried $\mathrm{MeOH}(10 \mathrm{~mL})$ was slowly added and the mixture stirred for 30 min. Then 4'-[4(bromomethyl)phenyl]-2,2':6',2"'-terpyridine (0.350 $\mathrm{g}, 0.89 \mathrm{mmol})$ in dried $\mathrm{MeOH}(10 \mathrm{~mL})$ was slowly added and the mixture stirred overnight. Dichloromethane was added and the mixture was washed three times with $\mathrm{HNaCO}_{3}$ and with water. After extraction, the organic layers were collected dried over MgSO4 and the solvent was evaporated under vacuum. The obtained residue was purified by chromatography on silica gel with $\mathrm{CH}_{2} \mathrm{Cl}_{2} / \mathrm{AcOEt}(4: 1)$ to give the pure desired ligand as an orange powder, yield $284 \mathrm{mg}(56 \%)$. Melting point: 143․ IR (KBr pellet): $506(\mathrm{~m}), 618(\mathrm{w})$, $659(\mathrm{w}), 688(\mathrm{w}), 730(\mathrm{~m}), 745(\mathrm{~m}), 768(\mathrm{~m}), 789(\mathrm{~s}), 835(\mathrm{~m}), 888(\mathrm{~m}), 965$ $(w), 990(w), 1039(w), 1083(w), 1117(w), 1229(w), 1315(w), 1385(s)$, 1418 (s), 1466 (s), $1512(\mathrm{~m}), 1544(\mathrm{~m}), 1565$ (m), $1583(\mathrm{~s}), 1604$ (w), 2251 (w), $2913(w), 2985(w), 3012(w), 3048$ (w) $\mathrm{cm}^{-1}$. Anal. Calc. (\%) for $\mathrm{C}_{33} \mathrm{H}_{26} \mathrm{~N}_{4} \mathrm{~S}_{8}$ : calcd. C 53.95, H 3.54, N 7.63; found C 53.88, H 3.61, N 7.52. ${ }^{1} \mathrm{H}$ NMR $\left(\mathrm{CDCl}_{3}\right): \delta=8.77(\mathrm{~s}, 2 \mathrm{H}), 8.75(\mathrm{~m}, 2 \mathrm{H}), 8.70(\mathrm{~d}, 2 \mathrm{H}), 7.94(\mathrm{dd}$, $2 \mathrm{H}), 7.90$ (d, $2 \mathrm{H}), 7.50$ (d, $2 \mathrm{H}), 7.38$ (dd, 2H), 4.13 (s, 2H), 2.86 (t, $2 \mathrm{H})$, $2.46(\mathrm{~s}, 6 \mathrm{H}), 2.43(\mathrm{t}, 2 \mathrm{H}) \mathrm{ppm}$.
\end{abstract}

4-(4'-Methyl-phenyl-2,2:6',2''-terpyridine -4-yImethylthio)-5-(2cyanoethylthio)-4',5'-bis(propylthio)tetrathiafulvene $\left(L^{2}\right): 4,5-b i s(2-$ cyanoethylthio)-4',5'-bis(propylthio)tetrathiafulvalene ${ }^{[31]} \quad\left(\begin{array}{lll}0.700 & \mathrm{~g}, & 1.34\end{array}\right.$ $\mathrm{mmol}$ ) was dissolved in anhydrous degassed dimethyformamide (DMF) $(10 \mathrm{~mL})$ under argon. Then $\mathrm{CsOH} \cdot \mathrm{H}_{2} \mathrm{O}(229 \mathrm{mg}, 1.36 \mathrm{mmol})$ in dried $\mathrm{MeOH}(10 \mathrm{~mL})$ was slowly added and the mixture stirred for $30 \mathrm{~min}$. Then 4'-[4-(bromomethyl)phenyl]-2,2':6',2"'-terpyridine $(0.700 \mathrm{~g}, 1.74 \mathrm{mmol})$ in dried $\mathrm{MeOH}(15 \mathrm{~mL}$ ) was slowly added and the mixture stirred overnight. Dichloromethane was added and the mixture was washed three times with $\mathrm{HNaCO}_{3}$ and with water. After extraction, the organic layers were collected dried over MgSO4 and the solvent was evaporated under vacuum. The obtained residue was purified by chromatography on silica gel with $\mathrm{CH}_{2} \mathrm{Cl}_{2} / \mathrm{AcOEt}(4: 1)$. Recrystallization in $\mathrm{CH}_{2} \mathrm{Cl}_{2} / n$-hexane mixture gave the pure desired ligand as an orange powder, yield $476 \mathrm{mg}(45 \%)$. Melting point: $135^{\circ}$. IR (KBr pellet): $508(\mathrm{~m}), 619(\mathrm{w}), 660(\mathrm{w}), 688(\mathrm{w}), 744(\mathrm{~m})$, $790(\mathrm{~s}), 835(\mathrm{~m}), 890(\mathrm{~m}), 965(\mathrm{w}), 991(\mathrm{w}), 1039(\mathrm{w}), 1088(\mathrm{w}), 1233(\mathrm{w})$, 1290 (w), 1386 (s), 1416 (s), $1465(\mathrm{~s}), 1514(\mathrm{~m}), 1547(\mathrm{~m}), 1565(\mathrm{~m}), 1583$ (s), 1605 (w), 2251 (w), 2869 (w), 2929 (w), 2960 (m), $3012(w), 3049(w)$ $\mathrm{cm}^{-1}$. Anal. Calc. (\%) for $\mathrm{C}_{37} \mathrm{H}_{36} \mathrm{~N}_{4} \mathrm{~S}_{8}$ : calcd. C 56.20, H 4.56, N 7.09; found C 56.07, H 4.64, N 7.02. ${ }^{1} \mathrm{H}$ NMR $\left(\mathrm{CDCl}_{3}\right): \delta=8.76(\mathrm{~s}, 2 \mathrm{H}), 8.75(\mathrm{~m}, 2 \mathrm{H})$,
8.70 (d, 2 H), 7.92 (dd, 2 H), 7.90 (d, 2 H), 7.49 (d, 2 H), 7.38 (dd, 2H) $4.13(\mathrm{~s}, 2 \mathrm{H}), 2.86(\mathrm{~m}, 2 \mathrm{H}), 2.83(\mathrm{~m}, 4 \mathrm{H}), 2.44(\mathrm{t}, 2 \mathrm{H}), 1.70(\mathrm{tt}, 4 \mathrm{H}), 1.04$ (dd, 6 H) ppm.

$\left[\mathrm{Ni}\left(\mathrm{L}^{1}\right)_{2}\right]\left(\mathrm{NO}_{3}\right)_{2}$ (1): $5.7 \mathrm{mg}$ of $\mathrm{Ni}\left(\mathrm{NO}_{3}\right)_{2} \cdot 6 \mathrm{H}_{2} \mathrm{O}(0.02 \mathrm{mmol})$ and $29 \mathrm{mg}$ of $\mathrm{L}^{1}$ ( $0.04 \mathrm{mmol}$ ) were dissolved in $14 \mathrm{~mL}$ of $\mathrm{CH}_{3} \mathrm{CN}$ and heated to reflux for 3 $\mathrm{h}$ under argon atmosphere. After cooling to room temperature, slow diffusion of $\mathrm{Et}_{2} \mathrm{O}$ vapour into the mother solution led to the formation of

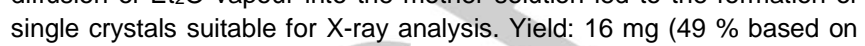
single crystals). IR (KBr pellet): $419(\mathrm{w}), 508(\mathrm{w}), 640(\mathrm{w}), 658(\mathrm{~m}), 692(\mathrm{w})$, $732(w), 751(w), 771(w), 792(s), 828(w), 889(m), 1015(m), 1160(w)$, $1250(\mathrm{w}), 1344(\mathrm{~m}), 1364(\mathrm{~s}), 1384(\mathrm{~s}), 1405(\mathrm{~m}), 1473(\mathrm{~s}), 1551(\mathrm{~m}), 1602$ (s), 1613 (s), 2249 (w), 2917 (w), 3058 (w) cm-1. Anal. Calc. (\%) for $\mathrm{C}_{66} \mathrm{H}_{52} \mathrm{~N}_{10} \mathrm{NiO}_{6} \mathrm{~S}_{16}$ : calcd. C 47.92, H 3.15, N 8.47; found C 47.87, H 3.24, N 8.42 .

[Co( $\left.\left(\mathrm{L}^{1}\right)_{2}\right]\left(\mathrm{NO}_{3}\right)_{2}(2): 5.8 \mathrm{mg}$ of $\mathrm{Co}\left(\mathrm{NO}_{3}\right)_{2} \cdot 6 \mathrm{H}_{2} \mathrm{O}(0.02 \mathrm{mmol})$ and $29 \mathrm{mg}$ of $\mathrm{L}^{1}(0.04 \mathrm{mmol})$ were dissolved in $15 \mathrm{~mL}$ of $\mathrm{CH}_{3} \mathrm{CN} / \mathrm{DMF}(1: 1$ in volume) and heated to reflux for $3 \mathrm{~h}$ under argon atmosphere. After cooling to room temperature, slow diffusion of $\mathrm{Et}_{2} \mathrm{O}$ vapour into the mother solution led to the formation of single crystals suitable for X-ray analysis. Yield: $23 \mathrm{mg}$ (71\% based on single crystals). IR (KBr pellet): $512(\mathrm{~m}), 658(\mathrm{w}), 750(\mathrm{~m})$, $791(\mathrm{~s}), 830(\mathrm{~m}), 887(\mathrm{~m}), 967(\mathrm{w}), 1016(\mathrm{w}), 1161(\mathrm{w}), 1248(\mathrm{~m}), 1360(\mathrm{~s})$, $1381(\mathrm{~s}), 1405$ (m), $1429(\mathrm{~m}), 1471(\mathrm{~s}), 1545(\mathrm{~m}), 1612(\mathrm{~s}), 1668(\mathrm{w}), 2248$ (w), 2917 (w), 3058 (w) cm $\mathrm{cm}^{-1}$. Anal. Calc. (\%) for $\mathrm{C}_{66} \mathrm{H}_{52} \mathrm{~N}_{10} \mathrm{CoO}_{6} \mathrm{~S}_{16}$ : calcd. C 47.91, H 3.15, N 8.47; found C 47.80, H 3.28, N 8.41.

[Co( $\left.\left(\mathrm{L}^{1}\right)_{2}\right]\left(\mathrm{BF}_{4}\right)_{2}(3): 6.8 \mathrm{mg}$ of $\mathrm{Co}\left(\mathrm{BF}_{4}\right)_{2} \cdot 6 \mathrm{H}_{2} \mathrm{O}(0.02 \mathrm{mmol})$ and $29 \mathrm{mg}$ of $\mathrm{L}^{1}$ $(0.04 \mathrm{mmol})$ were dissolved in $15 \mathrm{~mL}$ of DMF (1:1 in volume) and heated to $85^{\circ} \mathrm{C}$ for $3 \mathrm{~h}$ under argon atmosphere. After cooling to room temperature, slow diffusion of $\mathrm{Et}_{2} \mathrm{O}$ vapour into the mother solution led to the formation of single crystals suitable for X-ray analysis. Yield: $25 \mathrm{mg} \mathrm{(74 \%} \mathrm{based} \mathrm{on}$ single crystals). IR (KBr pellet): $516(\mathrm{~m}), 660(\mathrm{w}), 751(\mathrm{~m}), 792(\mathrm{~s}), 887(\mathrm{~m})$, $1058(\mathrm{~s}), 1078(\mathrm{~s}), 1248(\mathrm{w}), 1410(\mathrm{~m}), 1430(\mathrm{~m}), 1472(\mathrm{~m}), 1545(\mathrm{w}), 1612$ (s), $1667(\mathrm{~m}), 2248(\mathrm{w}), 2918(\mathrm{w}), 3066(\mathrm{w}) \mathrm{cm}^{-1}$. Anal. Calc. (\%) for $\mathrm{C}_{66} \mathrm{H}_{52} \mathrm{~N}_{10} \mathrm{CoB}_{2} \mathrm{~F}_{8} \mathrm{~S}_{16}$ : calcd. C 46.52, H 3.05, N 8.22; found C 46.39, H 3.04, N 8.29.

[CoCl$\left.{ }_{2}\left(\mathbf{L}^{1}\right)\right] \cdot 2 \mathrm{DMF}(4) .5 .2 \mathrm{mg}$ of $\mathrm{CoCl}_{2}(0.04 \mathrm{mmol})$ and $29.3 \mathrm{mg}$ of $\mathbf{L}^{\mathbf{1}}$ $(0.04 \mathrm{mmol})$ were dissolved in $14 \mathrm{~mL}$ of DMF and heated to $85^{\circ} \mathrm{C}$ for $3 \mathrm{~h}$ under argon atmosphere. After cooling to room temperature, slow diffusion of $\mathrm{Et}_{2} \mathrm{O}$ vapour into the mother solution led to the formation of single

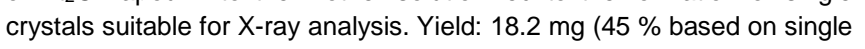
crystals). IR (KBr pellet): $415(\mathrm{w}), 513(\mathrm{~m}), 639(\mathrm{w}), 658(\mathrm{~m}), 691(\mathrm{~m}), 731$ $(\mathrm{m}), 750(\mathrm{~m}), 771(\mathrm{~m}), 791(\mathrm{~s}), 889(\mathrm{~m}), 1014(\mathrm{~m}), 1161(\mathrm{w}), 1249(\mathrm{~m})$, 1403 (s), 1430 (s) 1472 (s), 1547 (m), 1570 (m), 1602 (s), 1611 (s), 2250 (w), 2918 (w), 3057 (w) cm $\mathrm{cm}^{-1}$. Anal. Calc. (\%) for $\mathrm{C}_{33} \mathrm{H}_{26} \mathrm{~N}_{4} \mathrm{CoCl}_{2} \mathrm{~S}_{8}$ : calcd. C 45.84, H 3.01, N 6.48; found C 45.74, H 3.07, N 6.32.

[CoBr $\left.{ }_{2}\left(\mathbf{L}^{1}\right)\right]$.DMF (5). $8.7 \mathrm{mg}$ of $\mathrm{CoBr}_{2}(0.04 \mathrm{mmol})$ and $29.3 \mathrm{mg}$ of $\mathbf{L}^{\mathbf{1}}(0.04$ $\mathrm{mmol}$ ) were dissolved in $14 \mathrm{~mL}$ of DMF and heated to reflux for $3 \mathrm{~h}$ under argon atmosphere. After cooling to room temperature, slow diffusion of $\mathrm{Et}_{2} \mathrm{O}$ vapor into the mother solution led to the formation of single crystals suitable for X-ray analysis. Yield: $23.4 \mathrm{mg}$ (57\% based on single crystals). IR (KBr pellet): $510(w), 659(w), 730(w), 752(w), 793(s), 885(s), 1017$ (w), $1088(\mathrm{w}), 1251(\mathrm{~m}), 1406(\mathrm{~m}), 1473(\mathrm{~m}), 1608(\mathrm{~s}), 1661(\mathrm{~s}), 2248(\mathrm{w})$, 2914 (w), 2974 (w), 3058 (w) cm $\mathrm{cm}^{-1}$. Anal. Calc. (\%) for $\mathrm{C}_{33} \mathrm{H}_{26} \mathrm{~N}_{4} \mathrm{CoS}_{8}$ : calcd. C 41.51, H 2.73, N 5.87; found C 41.37, H 2.84, N 5.82 .

$\left[\mathrm{CoCl}_{2}\left(\mathrm{~L}^{2}\right)\right] \cdot \mathrm{DMF} \cdot \mathbf{0 . 5}\left(\mathrm{Et}_{2} \mathrm{O}\right)$ (6). $5.2 \mathrm{mg}$ of $\mathrm{CoCl}_{2}(0.04 \mathrm{mmol})$ and $31.6 \mathrm{mg}$ of $\mathrm{L}^{2}(0.04 \mathrm{mmol})$ were dissolved in $14 \mathrm{~mL}$ of DMF and heated to $85^{\circ} \mathrm{C}$ for $3 \mathrm{~h}$ under argon atmosphere. After cooling to room temperature, slow diffusion of $\mathrm{Et}_{2} \mathrm{O}$ vapour into the mother solution led to the formation of 
single crystals suitable for X-ray analysis. Yield: $17.1 \mathrm{mg} \mathrm{(42 \%} \mathrm{based} \mathrm{on}$ single crystals). IR (KBr pellet): 510 (w), 637 (w), 660 (w), 731 (w), 750 (w), $791(\mathrm{~s}), 881(\mathrm{~m}), 1016(\mathrm{~m}), 1247(\mathrm{~m}), 1404(\mathrm{~m}), 1426(\mathrm{~m}), 1471(\mathrm{~s}), 1546$ $(\mathrm{m}), 1608(\mathrm{~s}), 2252(\mathrm{w}), 2869(\mathrm{w}), 2925(\mathrm{w}), 2960(\mathrm{~m}), 3012(\mathrm{w}), 3059(\mathrm{w})$ $\mathrm{cm}^{-1}$. Anal. Calc. (\%) for $\mathrm{C}_{38} \mathrm{H}_{34} \mathrm{~N}_{4} \mathrm{CoCl}_{2} \mathrm{~S}_{8}$ : calcd. C 48.87, H 3.64, N 6.00; found C 48.69, H 3.74, N 6.02.

[CoBr $\left.{ }_{2}\left(\mathrm{~L}^{2}\right)\right]$.DMF (7). $8.7 \mathrm{mg}$ of $\mathrm{CoBr}_{2}(0.04 \mathrm{mmol})$ and $31.6 \mathrm{mg}$ of $\mathrm{L}^{2}(0.04$ mmol) were dissolved in $14 \mathrm{~mL}$ of DMF and heated to $85^{\circ} \mathrm{C}$ for $3 \mathrm{~h}$ under argon atmosphere. After cooling to room temperature, slow diffusion of $\mathrm{Et}_{2} \mathrm{O}$ vapour into the mother solution led to the formation of single crystals suitable for X-ray analysis. Yield: $19.9 \mathrm{mg}$ (46\% based on single crystals). IR (KBr pellet): $510(\mathrm{w}), 638(\mathrm{w}), 659(\mathrm{w}), 734(\mathrm{w}), 752(\mathrm{w}), 790(\mathrm{~s}), 885$ $(\mathrm{m}), 1017(\mathrm{~m}), 1245(\mathrm{~m}), 1404(\mathrm{~m}), 1421(\mathrm{~m}), 1469(\mathrm{~s}), 1545(\mathrm{~m}), 1608(\mathrm{~s})$, 1661 (s) 2252 (w), 2869 (w), 2925 (w), $2960(\mathrm{~m}), 3012(w), 3059(w) \mathrm{cm}^{-}$ 1. Anal. Calc. (\%) for $\mathrm{C}_{38} \mathrm{H}_{34} \mathrm{~N}_{4} \mathrm{CoBr}_{2} \mathrm{~S}_{8}$ : calcd. C 45.15, H 3.37, N 5.54; found C 45.09, H 3.24, N 5.62 .

Single crystal X-ray structure analysis. Single crystals of 1-7 were mounted on a D8 VENTURE Bruker-AXS diffractometer for data collection $\left(\mathrm{MoK}_{\alpha}\right.$ radiation source, $\lambda=0.71073 \AA$ ), from the Centre de Diffractométrie X (CDIFX), Université de Rennes 1, France. Structures were solved with a direct method using the SHELXT program ${ }^{[32]}$ and refined with a full matrix least-squares method on $\mathrm{F}^{2}$ using the SHELXL-14/7 program ${ }^{[33]}$. Crystallographic data are summarized in Table S1. Complete crystal structure results as CIF files (CCDC 2070050 (for 5), 2070051 (for 4), 2070052 (for 3), 2070053 (for 6), 2070054 (for 2), 2070055 (for 7) and 2070056 (for 1)) including bond lengths, angles, and atomic coordinates are deposited as Supporting Information. These data are provided free of charge by the joint Cambridge Crystallographic Data Centre and Fachinformationszentrum Karlsruhe Access Structures service https://www.ccdc.cam.ac.uk/structures

Physical Measurements The elementary analyses of the compounds were performed at the Centre Regional de Mesures Physiques de l'Ouest, Rennes. ${ }^{1} \mathrm{H}$ NMR spectra were recorded with a Bruker Ascend 400 spectrometer. Chemical shifts are reported in parts per million referenced to TMS. Cyclic voltammetry was carried out in dried and degassed $\mathrm{CH}_{2} \mathrm{Cl}_{2}$ (for ligands) and DMF (for complexes) solution, containing $0.1 \mathrm{M}$ $\mathrm{N}\left(\mathrm{C}_{4} \mathrm{H}_{9}\right)_{4} \mathrm{PF}_{6}$ as supporting electrolyte. Voltammograms were recorded at $100 \mathrm{mVs}^{-1}$ at a platinum disk electrode. The potentials were measured vs. a saturated calomel electrode (SCE). The dc magnetic susceptibility measurements were performed on solid immobilized polycrystalline sample with a Quantum Design MPMS-XL SQUID magnetometer between 2 and $300 \mathrm{~K}$ in applied magnetic field of $0.02 \mathrm{~T}$ for temperatures of $2-20 \mathrm{~K}$, $0.2 \mathrm{~T}$ for temperature of $20-80 \mathrm{~K}$ and $1 \mathrm{~T}$ for temperatures of $80-400 \mathrm{~K}$. The highest temperature for dc measurements is $300 \mathrm{~K}$ for compounds which cannot display spin crossover behaviour (1 and 4-7) while it is $400 \mathrm{~K}$ for compounds highlighted spin crossover phenomena (2 and 3 ). The ac magnetic susceptibility measurements were performed on a Quantum Design PPMS magnetometers on the $50-10000 \mathrm{~Hz}$ frequency range. These measurements were all corrected for the diamagnetic contribution as calculated with Pascal's constants.

\section{Acknowledgements}

This work was supported by the Université de Rennes 1, CNRS, and the European Commission through the ERC-CoG 725184 MULTIPROSMM (project n. 725184). S.T. and L.K. thank the Algerian PNE program for the financial support during the stay in the French ISCR laboratory.
Keywords: Tetrathiafulvalene• Terpyridine • Transition Metal • Spin Crossover $\cdot$ Single-Molecule Magnet

[1] a) M. Affronte, F. Troiani, A. Ghirri, A. Candini, M. Evangelisti, V. Corradini, S. Carretta, P. Santini, G. Amoretti, F. Tuna, G. Timco, R. E. P. Winpenny, J. Phys. D: Appl. Phys. 2007, 40, 2999-3004; b) A Ardavan, O. Rival, J. J. L. Morton, S. J. Blundell, A. M. Tyryshkin, G. A Timco, R. E. P. Winpenny, Phys. Rev. Lett. 2007, 98, 057201; c) L. Bogani, W. Wernsdorfer, Nat. Mater. 2008, 7, 179-186; d) S. Sanvito, Chem. Soc. Rev. 2011, 40, 3336-3355; e) S. Lumetti, A. Candini, C Godfrin, F. Balestro, W. Wernsdorfer, S. Klyatskaya, M. Ruben, M. Affronte, Dalton Trans. 2016, 45, 16570-16574; f) A. R. Rocha, V. M García-Suárez, S. W. Bailey, C. J. Lambert, J. Ferrer, S. Sanvito, Nat. Mater. 2005, 4, 335-339; g) M. Affronte, J. Mater. Chem. 2009, 19, 1731-1737; h) R. Sessoli, M.-E. Boulon, A. Caneschi, M. Mannini, L. Poggini, F. Wilhelm, A. Rogalev, Nat. Phys. 2015, 11, 69-74; i) A. Ghirri, A. Candini, M. Affronte, Magnetochemistry 2017, 3, 12; j) A. Cornia, P. Seneor, Nat. Mater. 2017, 16, 505-506; k) M. Prezioso, A. Riminucci, P. Graziosi, I. Bergenti, R. Rakshit, R. Cecchini, A. Vianelli, F. Borgatti, N Haag, M. Willis, A. J. Drew, W. P. Gillin, V. Dediu, Adv. Mater. 2013, 25, 534-538.

[2] a) P. Gutlich, Y. Garcia, H. A. Goodwin, Chem. Soc. Rev. 2000, 29, 419 427; b) A. Bousseksou, G. Molnar, L. Salmon, W. Nicolazzi, Chem. Soc. Rev. 2011, 40, 3313-3335; c) M. C. Munoz, J. A. Real, Coord. Chem. Rev. 2011, 255, 2068-2093; d) G. Aromi, L. A. Barrios, O. Roubeau, P Gamez, Coord. Chem. Rev. 2011, 255, 485-546; e) M. A. Halcrow, Chem. Soc. Rev. 2011, 40, 4119-4142; f) M. A. Halcrow Spin-Crossover Materials-Properties and Applications, ed. John Wiley \& Sons, Ltd.: New York, 2013

[3] a) R. Sessoli, D. Gatteschi, A. Caneschi, M. A. Novak, Nature 1993, 365 141-143; b) G. Aromi, E. K. Brechin, in Single-Molecule Magnets and Related Phenomena (Ed.: R. Winpenny), 2006, p. 1-67.

[4] a) L. Thomas, L. Lionti, R. Ballou, D. Gatteschi, R. Sessoli, B. Barbara, Nature 1996, 383, 145-147; b) G. Christou, D. Gatteschi, D. N Hendrickson, R. Sessoli, MRS Bull. 2000, 25, 66-71; c) M. Murrie, Chem. Soc. Rev. 2010, 39, 1986-1995.

[5] a) R. Sessoli, A. K. Powell, Coord. Chem. Rev. 2009, 253, 2328-2341; b) M. Murrie, Chem. Soc. Rev. 2010, 39, 1986-1995; c) I. R. Jeon, R. Clérac, Dalton Trans. 2012, 41, 9569-9586; d) D. N. Woodruff, R. E. P. Winpenny, R. A. Layfield, Chem. Rev. 2013, 113, 5110-5148; e) K. Liu, W. Shi, P. Cheng, Coord. Chem. Rev. 2015, 289-290, 74-122; f) S. G. McAdams, A. M. Ariciu, A. K. Kostopoulos, J. P. S. Walsh, F. Tuna, Coord. Chem. Rev. 2017, 346, 216-239.

[6] a) S. Gomez-Coca, E. Cremades, N. Aliaga-Alcalde, E. Ruiz, J. Am Chem. Soc. 2013, 135, 7010-7018; b) G. A. Craig, M. Murrie, Chem Soc. Rev. 2015, 44, 2135-2147; c) J. Frost, K. L. M. Harriman, M. Murugesu, Chem. Sci. 2016, 7, 2470-2491; c) K. L. M. Harriman, M Murugesu, Acc. Chem. Res. 2016, 49, 1158-1167; d) J. Ferrando-Soria, J. Vallejo, M. Castellano, J. Martínez-Lillo, E. Pardo, J. Cano, I. Castro, F. Lloret, R. Ruiz-García, M. Julve, Coord. Chem. Rev. 2017, 339, 17-103.

[7] D. E. Freedman, W. H. Harman, T. D. Harris, G. J. Long, C. J. Chang, J R. Long, J. Am. Chem. Soc. 2010, 132, 1224-1225.

[8] a) J. M. Zadrozny, D. J. Xiao, M. Atanasov, G. J. Long, F. Grandjean, F. Neese, J. R. Long, Nat. Chem. 2013, 5, 577-581; b) J. M. Zadrozny, D J. Xiao, J. R. Long, M. Atanasov, F. Neese, F. Grandjean, G. J. Long Inorg. Chem. 2013, 52, 13123-13131; c) P. P. Samuel, K. C. Mondal, N. Amin Sk, H. W. Roesky, E. Carl, R. Neufeld, D. Stalke, S. Demeshko, F. Meyer, L. Ungur, L. F. Chibotaru, J. Christian, V. Ramachandran, J. van-Tol, N. S. Dalal, J. Am. Chem. Soc. 2014, 136, 11964-11971; d) J. M. Zadrozny, M. Atanasov, A. M. Bryan, C.-Y. Lin, B. D. Rekken, P. P. Power, F. Neese, J. R. Long, Chem. Sci. 2013, 4, 125-138; e) M. Atanasov, J. M. Zadrozny, J. R. Long, F. Neese, Chem. Sci. 2013, 4, 139-156; f) P.-H. Lin, N. C. Smythe, S. I. Gorelsky, S. Maguire, N. J. 
Henson, I. Korobkov, B. L. Scott, J. C. Gordon, R. T. Baker, M. Murugesu, J. Am. Chem. Soc. 2011, 133, 15806-15809; g) D. E. Freedman, W. H. Harman, T. D. Harris, G. J. Long, C. J. Chang, J. R. Long, J. Am. Chem. Soc. 2010, 132, 1224-1225; h) A. V. Palii, J. M. Clemente-Juan, E. Coronado, S. I. Klokishner, S. M. Ostrovsky, O. S. Reu, Inorg. Chem. 2010, 49, 8073-8077; i) W. H. Harman, T. D. Harris, D. E. Freedman, H. Fong, A. Chang, J. D. Rinehart, A. Ozarowski, M. T. Sougrati, F. Grandjean, G. J. Long, J. R. Long, C. Chang, J. Am. Chem. Soc. 2010 132, 18115-18126; j) D. Weismann, Y. Sun, Y. Lan, G. Wolmershäuser, A. K. Powell, H. Sitzmann, Chem. - Eur. J. 2011, 17, 4700-4704; k) C. Mathonière, H.-J. Lin, D. Siretanu, R. Clérac, J. M. Smith, J. Am. Chem. Soc. 2013, 135, 19083-19086; I) X. Feng, C. Mathonière, I-R. Jeon, M. Rouzières, A. Ozarowski, M. L. Aubrey, M. I. Gonzalez, R. Clérac, J. R. Long, J. Am. Chem. Soc. 2013, 135, 15880-15884; m) S. Mossin, B. L. Tran, D. Adhikari, M. Pink, F. W. Heinemann, J. Sutter, R. K. Szilagyi, K. Meyer, D. J. Mindiola, J. Am. Chem. Soc. 2012, 134, 13651-13661; n) M. Atanasov, D. Ganyushin, D. A. Pantazis, K. Sivalingam, F. Neese, Inorg. Chem. 2011, 50, 7460-7477.

[9] a) Y.-S. Meng, Z.-B. Mo, B.-W. Wang, Y.-Q. Zhang, L. Deng, S. Gao, Chem. Sci. 2015, 6, 7156-7162; b) S. Gómez-Coca, E. Cremades, N. Aliaga-Alcalde, E. Ruiz, J. Am. Chem. Soc. 2013, 135, 7010-7018; c) Y.Y. Zhu, C. Cui, Y.-Q Zhang, J.-H. Jia, X. Guo, C. Gao, K. Qian, S.-D. Jiang, B.-W. Wang, Z.-M. Wang, S. Gao, Chem. Sci. 2013, 4, 1802-1806; d) Y.-Y. Zhu, Y.-Q. Zhang, T.-T. Yin, C. Gao, B.-W. Wang, S. Gao, Inorg. Chem. 2015, 54, 5475-5486; e) V. V. Novikov, A. A. Pavlov, Y. V. Nelyubina, M.-E. Boulon, O. A. Varzatskii, Y. Z. Voloshin, R. E. P. Winpenny, J. Am. Chem. Soc. 2015, 137, 9792-9795; f) R Herchel, L. Váhovská, I. Potocňák, Z. Trávnícěk, Inorg. Chem. 2014, 53, 5896-5898; g) J. Vallejo, I. Castro, R. Ruiz-García, J. Cano, M. Julve, F. Lloret, G. De Munno, W. Wernsdorfer, E. Pardo, J. Am. Chem. Soc. 2012 , 134, 15704-15707; h) R. Díaz-Torres, M. Menelaou, O. Roubeau, A. Sorrenti, G. Brandariz-de-Pedro, E. C. Sañudo, S. Teat, J. J. Fraxedas, E. Ruiz, N. Aliaga-Alcalde, Chem. Sci. 2016, 7, 2793-2803; i) S. GómezCoca, A. Urtizberea, E. Cremades, P. J. Alonso, A. Camón, E. Ruiz, F. Luis, Nat. Commun. 2014, 5, 4300; j) E. Colacio, J. Ruiz, E. Ruiz, E. Cremades, J. Krzystek, S. Carretta, J. Cano, T. Guidi, W. Wernsdorfer, E. K. Brechin, Angew. Chem., Int. Ed. 2013, 52, 9130-9134; k) D.-Y. Wu, X.-X. Zhang, P. Huang, W. Huang, M.-Y. Ruan, Z. W. Ouyang, Inorg Chem. 2013, 52, 10976-10982; I) V. Chandrasekhar, A. Dey, A. J. Mota, E. Colacio, Inorg. Chem. 2013, 52, 4554-4561; m) A. Eichhöfer, Y. Lan, V. Mereacre, T. Bodenstein, F. Weigend, Inorg. Chem. 2014, 53, 1962-1974; n) J. M. Zadrozny, J.-J. Liu, N. A. Piro, C. J. Chang, S. Hill, J. R. Long, Chem. Commun. 2012, 48, 3927-3929; o) F. Yang, Q. Zhou, Y.-Q. Zhang, G. Zeng, G-H. Li, Z. Shi, B.-W. Wang, S.-H. Feng, Chem. Commun. 2013, 49, 5289-5291; p) D.-K. Cao, J.-Q. Feng, M. Ren, Y.W. Gu, Y. Song, M. D. Ward, Chem. Commun. 2013, 49, 8863-8865; q) W. Huang, T. Liu, D.-Y. Wu, J.-J. Cheng, Z. W. Ouyang, C.-Y. Duan, Dalton Trans. 2013, 42, 15326-15331; r) T. Jurca, A. Farghal, P.-H. Lin, I. Korobkov, M. Murugesu, D. S. Richeson, J. Am. Chem. Soc. 2011, 133, 15814-15817; s) F. Habib, O. R. Luca, V. Vieru, M. Shiddiq, I. Korobkov, S. I. Gorelsky, M. K. Takase, L. F. Chibotaru, S. Hill, R. H. Crabtree, M. Murugesu, Angew. Chem., Int. Ed. 2013, 52, 11290-11293; t) Y. Peng, T. Bodenstein, K. Fink, V. Mereacre, C. E. Anson, A. K. Powell, Phys. Chem. Chem. Phys. 2016, 18, 30135-30143; u) R. Ruamps, L. J. Batchelor, R. Maurice, N. Gogoi, P. Jiménez- Lozano, N. Guihéry, C. de Graaf, A.-L. Barra, J.-P. Sutter, T. Mallah, Chem. - Eur. J. 2013, 19, 950-956; v) B. Cahier, M. Perfetti, G. Zakhia, D. Naoufal, F. El-Khatib, R. Guillot, R. Sessoli, A.-L. Barra, N. Guihéry, T. Mallah, Chem.-Eur. J. 2017, 23, 3648-3657; w) D. Schweinfurth, M. G. Sommer, M. Atanasov, S. Demeshko, S. Hohloch, F. Meyer, F. Neese, B. Sarkar, J. Am. Chem. Soc. 2015, 137, 1993-2005. x) J. Krzystek, J. Telser, Dalton Trans. 2016, 45, 16751-16763; y) F. Shao, B. Cahier, E. Rivière, R. Guillot, N. Guihéry, V. E. Campbell, T. Mallah, Inorg. Chem. 2017, 56, 1104-1111; z) E. A. Suturina, J. Nehrkorn, J. M. Zadrozny, J. Liu, M. Atanasov, T.
Weyhermüller, D. Maganas, S. Hill, A. Schnegg, E. Bill, J. R. Long, F. Neese, Inorg. Chem. 2017, 56, 3102-3118.

[10] a) M. Ding, G. E. Cutsail, D. Aravena, M. Amoza, M. Rouzières, P. Dechambenoit, Y. Losovyj, M. Pink, E. Ruiz, R. Clérac, J. M. Smith, Chem. Sci. 2016, 7, 6132-6140; b) A. Pascual-Álvarez, J. Vallejo, E. Pardo, M. Julve, F. Lloret, J. Krzystek, D. Armentano, W. Wernsdorfer, J. Cano, Chem. - Eur. J. 2015, 21, 17299-17307.

[11] a) W. Lin, T. Bodenstein, V. Mereacre, K. Fink, A. Eichhofer, Inorg. Chem 2016, 55, 2091-2100; b) J. Miklovič, D. Valigura, R. Boča, J. Titiš, Dalton Trans. 2015, 44, 12484-12487; c) K. E. R. Marriott, L. Bhaskaran, C Wilson, M. Medarde, S. T. Ochsenbein, S. Hill, M. Murrie, Chem. Sci. 2015, 6, 6823-6828; d) R. C. Poulten, M. J. Page, A. G. Algarra, J. L. Le Roy, I. Lopez, E. Carter, A. Llobet, S. A. Macgregor, M. F. Mahon, D. M. Murphy, M. Murugesu, M. K. Whittlesey, J. Am. Chem. Soc. 2013, 135, 13640-13643.

[12] R. Boča, C. Rajnák, J. Titiš, D. Valigura, Inorg. Chem. 2017, 56, 1478-1482

[13] M. Atzori, L. Tesi, E. Morra, M. Chiesa, L. Sorace, R. Sessoli, J. Am. Chem. Soc. 2016, 138, 2154-2157.

[14] a) N. F. Chilton, Inorg. Chem. 2015, 54, 2097-2099; b) C. A. P. Goodwin F. Ortu, D. Reta, N. F. Chilton, D. P. Mills, Nature 2017, 548, 439-442; c) F.-S. Guo, B. M. Day, Y.-C Chen, M.-L. Tong, A. Mansikkamäki, R. A. Layfield, Science 2018, 362, 1400-1403.

[15] P. P. Power, Chem. Rev. 2012, 112, 3482-3507.

[16] a) F. Habib, O. R. Luca, V. Vieru, M. Shiddiq, I. Korobkov, S. I. Goresky, M. K. Takase, L. F. Chibotaru, S. Hill, R. H. Crabtree, M. Murugesu, Angew. Chem. Int. Ed. 2013, 52, 11290-11293; b) C. Rajnak, J. Titis, O Fuhr, M. Ruben, R. Boca, Inorg. Chem. 2014, 53, 8200-8202; c) A Switlicka, B. Machura, M. Penkala, A. Bienko, D. C. Bienko, J. Titis, C. Rajnak, R. Boca, A. Ozarowski, M. Ozerov, Inorg. Chem. 2018, 57, 12740-12755; d) J. Acharya, A. Sarkar, P. Kumar, V. Kumar, J. Flores Gonzalez, O. Cador, F. Pointillart, G. Rajaraman, V. Chandrasekhar, Dalton Trans. 2020, 49, 4785-4796.

[17] L. Cambi, A. Gagnasso, Atti. Accad. Naz. Lincei 1931, 13, 809-813.

[18] a) S. Hayami, Z. Z. Gu, M. Shiro, Y. Einaga, A. Fujishima, O. Sato, J. Am Chem. Soc. 2000, 122, 7126-7127; b) P. Gütlich, Y. Garcia, H. A. Goodwin, Chem. Soc. Rev. 2000, 29, 419-427; c) J. F. Letard, J. Mater Chem. 2006, 16, 2550-2559; d) B. Li, R.-J. Wei, J. Tao, R.-B. Huang, L. S. Zheng, Inorg. Chem. 2010, 49, 745-751; e) S. Hayami, Y. Komatsu, T. Shimizu, H. Kamihata, Y. H. Lee, Coord. Chem. Rev. 2011, 255, 1981-1990; f) S. Brooker, Chem. Soc. Rev. 2015, 44, 2880-2892; g) D. J. Harding, P. Harding, W. Phonsri, Coord. Chem. Rev. 2016, 313, 38-61; h) R. W. Hogue, S. Singh, S. Brooker, Chem. Soc. Rev. 2018, 47, 7303-7338.

[19] a) S. Hayami, Z.-Z. Gu, H. Yoshiki, A. Fujishima, O. Sato, J. Am. Chem Soc. 2001, 123, 11644-11650; b) A. Tsukiashi, M. Nakaya, F. Kobayashi, R. Ohtani, M. Nakamura, J. Harrowfield, Y. Kim, S. Hayami, Inorg. Chem. 2018, 57, 2834-2842.

[20] (a) H. A. Goodwin, Top. Curr. Chem. 2004, 234, 23-47; b) S. Hayami, Y Komatsu, T. Shimizu, H. Kamihata, Y. H. Lee, Coord. Chem. Rev. 2011, 255, 1981-1990; c) S. Brooker, P. G. Plieger, B. Moubaraki, K. S. Murray, Angew. Chem., Int. Ed. 1999, 38, 408-410; d) I. Krivokapic, M. Zerara, M. L. Daku, A. Vargas, C. Enachescu, C. Ambrus, P. Tregenna-Piggott, N. Amstutz, E. Krausz, A. Hauser, Coord. Chem. Rev. 2007, 251, 364 378; e) S. Hayami, K. Murata, D. Urakami, Y. Kojima, M. Akita, K. Inoue, Chem. Commun. 2008, 6510-6512; f) C. Ni, J. C. Fettinger, G. J. Long, P. P. Power, Inorg. Chem. 2009, 48, 2443-2448; g) G. Agustí, C. Bartual, V. Martínez, F. J. Munoz-Lara, A. B. Gaspar, M. C. Munoz, J. A. Real, New J. Chem. 2009, 33, 1262-1267; h) J. Zarembowitch, O. Kahn, Inorg. Chem. 1984, 23, 589-593; J. Zarembowitch, R. Claude, O. Kahn, Inorg. Chem. 1985, 24, 1576-1580; i) O. Thuery, J. Zarembowitch, Inorg. Chem. 1986, 25, 2001-2008; i) M. G. Cowan, J. Olguin, S. Narayanaswamy, J. L. Tallon, S. Brooker, J. Am. Chem. Soc. 2012, 134, $2892-2894$.

[21] a) R. C. Stoufer, D. W. Smith, E. A. Clevenger, T. E. Norris, Inorg. Chem. 1966, 5, 1167-1171; b) J. S. Judge, W. A. Baker jr., Inorg. Chim. Acta 
1967, 1, 68-72; c) C. M. Harris, T. N. Lockyear, R. L. Martin, H. R. H. Patil, E. Sinn, I. M. Stewart, Aust. J. Chem. 1969, 22, 2105-2116; d) H. Oshio, H. Spiering, V. Ksenofontov, F. Renz, P. Gutlich, Inorg. Chem. 2001, 40, 1143-1150; e) B. N. Figgis, E. S. Kucharski, A. H. White, Aust. J. Chem. 1983, 36, 1537-1561; f) S. Kremer, W. Henke, D. Reinen, Inorg. Chem. 1982, 21, 3013-3015; g) C. Enachescu, I. Krivokapic, M. Zerara, J. A. Real, N. Amstutz, A. Hauser, Inorg. Chim. Acta 2007, 360, 39453950; h) I. Krivokapic, M. Zerara, M. L. Daku, A. Vargas, C. Enachescu, C. Ambrus, P. Tregenna-Piggott, N. Amstutz, E. Krausz, A. Hauser, Coord. Chem. Rev. 2007, 251, 364-378; i) X.-P. Zhou, W.-X. Ni, S.-Z. Zhan, J. Ni, D. Li, Y.-G. Yin, Inorg. Chem. 2007, 46, 2345-2347; j) C. A. Kilner, M. A. Halcrow, Dalton Trans. 2010, 39, 9008-9012.

[22] a) H. Xie, K. R. Vignesh, X. Zhang, K. R. Dunbar, J. Mater. Chem. C 2020, 8, 8135-8144 ; b) F. Kobayashi, Y. Komatsumaru, R. Akiyoshi, M. Nakamura, Y. Zhang, L. F. Lindoy, S. Hayami, Inorg. Chem. 2020, 59, 16843-1852.

[23] a) M. Nihei, N. Takahashi, H. Nishikawa, H. Oshio, Dalton Trans. 2011, 40, 2154-2156; b) F. Pointillart, X. Liu, M. Kepenekian, B. Le Guennic, S. Golhen, V. Dorcet, T. Roisnel, O. Cador, Z. You, J. Hauser, S. Decurtins, L. Ouahab, S.-X. Liu, Dalton Trans. 2016, 45, 11267-11271; c) A. Kawamura, J. Xie, J.-N. Boyn, K. A. Jesse, A. J. McNeece, E. A. Hill, K. A. Collins, J. A. Valdez-Moreira, A. S. Filatov, J. W. Kurutz, D. A. Mazziotti, J. S. Anderson, J. Am. Chem. Soc. 2020, 142, 17670-17680; d) K. Mitsumoto, H. Nishikawa, G. N. Newton, H. Oshio, Dalton Trans. 2012, 41, 13601-13608.

[24] a) Q. Wang, P. Day, J.-P. Griffiths, H. Nie, J. D. Wallis, New J. Chem. 2006, 30, 1790-1800; b) E. Belhadj, A. El-Ghayoury, M. Mazari, M. Sallé, Tetrahedron Lett. 2013, 54, 3051-3054; c) E. Belhadj, A. El-Ghayoury, E. Ripaud, L. Zorina, M. Allain, P. Batail, M. Mazari, M. Sallé, New J. Chem. 2013, 37, 1427-1436; d) L. Hu, W. Liu, C.-H. Li, X.-H. Zhou, J.-L. Zuo, Eur. J. Inorg. Chem. 2013, 6037-6048.

[25] a) A. E. Jones, C. A. Christensen, D. F. Perepichka, A. S. Batsanov, A. Beeby, P. J. Low, M. R. Bryce, A. W. Parker, Chem. Eur. J. 2001, 7, 973978; b) W. F. Cooper, J. W. Edmonds, F. Wudl, P. Coppens, Cryst. Struct. Commun. 1974, 3, 23-26; c) A. Ellern, J. Bernstein, J. Y. Becker, S. Zamir, L. Shahal, S. Cohen, Chem. Mater. 1994, 6, 1378-1385.

[26] T. Ayers, S. Scott, J. Goins, N. Caylor, D. Hathcock, S. J. Slattery, D. L. Jameson, Inorg. Chim. Acta 2000, 307, 7-12.

[27] C. J. O'Connor, Prog. Inorg. Chem. 1982, 29, 203.

[28] a) C. Enachescu, I. Krivokapic, M. Zerara, J. A. Real, N. Amstutz, A. Hauser, Inorg. Chim. Acta 2007, 360, 3945-3950; b) I. Krivokapic, M. Zerara, M. L. Daku, A. Vargas, C. Enachescu, C. Ambrus, P. TregennaPiggott, N. Amstutz, E. Krausz, A. Hauser, Coord. Chem. Rev. 2007, 251, 364-378.

[29] C. Harris, T. Lockyer, R. Martin, H. Patil, E. Sinn, Aust. J. Chem. 1969, 22, 2105-2116.

[30] A. Pau, A. P. C. Ribeiro, A. Karmakar, M. Fatima, C. Guedes da Silva, A. J. L. Pombeiro, Dalton Trans. 2016, 45, 12779-12789.

[31] L. Binet, J. M. Fabre, C. Montginoul, K. B. Simonsen, J. Becher, J. Chem. Soc. Perkin Trans. 1 1996, 783-788.

[32] G. M. Sheldrick, Acta Crystallogr., Sect. A: Found Adv. 2015, 71, 3-8.

[33] G. M. Sheldrick, Acta Crystallogr., Sect. C: Struct. Chem. 2015, 71, 3-8. 
WILEY-VCH

\section{FULL PAPER}

Either thermal spin crossover or slow magnetic relaxation can be observed associating $\mathrm{Co}(\mathrm{II})$ ion with terpyridine decorated TTF ligands. Magnetization relaxed through Raman or Raman/Direct combination process depending of the $\mathrm{Co}$ (II) surrounding.

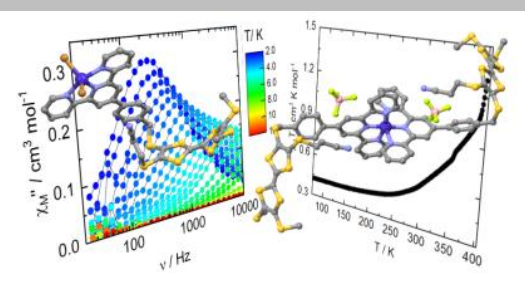

Spin Crossover and Single-Molecule Magnet

Siham Tiaouinine, Jessica Flores Gonzalez, Bertrand Lefeuvre, Marie Cordier, Vincent Dorcet, Lakehmici Kaboub, Olivier Cador, and Fabrice Pointillart, *

Page No. - Page No.

Spin Crossover and Field-Induced Single-Molecule Magnet Behaviour in Co(II) Complexes Based on Terpyridine with Tetrathiafulvalene Analogues 